\title{
Meta-Analysis of the Effects of Qol and DMI Fungicide Combinations on Fusarium Head Blight and Deoxynivalenol in Wheat
}

P. A. Paul, ${ }^{\dagger}$ Department of Plant Pathology, The Ohio State University, Ohio Agricultural Research and Development Center, Wooster 44691; C. A. Bradley, Department of Plant Pathology, University of Kentucky Research and Education Center, Princeton 42445; L. V. Madden and F. Dalla Lana, Department of Plant Pathology, The Ohio State University, Ohio Agricultural Research and Development Center; G. C. Bergstrom, Plant Pathology and Plant-Microbe Biology Section, School of Integrative Plant Science, Cornell University, Ithaca, NY 14853; R. Dill-Macky, Department of Plant Pathology, University of Minnesota, St. Paul 55108; P. D. Esker, Department of Plant Pathology and Environmental Microbiology, Penn State University, University Park 16802; K. A. Wise, Department of Botany and Plant Pathology, Purdue University, West Lafayette, IN 47907; M. McMullen, North Dakota State University, Department of Plant Pathology, Fargo 58108; A. Grybauskas, Department of Plant Science and Landscape Architecture, University of Maryland, College Park 20742; W. W. Kirk, Department of Plant, Soil and Microbial Sciences, Michigan State University, East Lansing 48824; E. Milus, Department of Plant Pathology, University of Arkansas, Fayetteville 72701; and K. Ruden, Plant Science Department, South Dakota State University, Brookings 57007

\begin{abstract}
Field trials were conducted in 17 U.S. states to evaluate the effects of quinone outside inhibitor (QoI) and demethylation inhibitor (DMI) fungicide programs on Fusarium head blight index (IND) and deoxynivalenol (DON) toxin in wheat. Four DMI-only treatments applied at Feekes 10.5.1, five QoI-only treatments applied between Feekes 9 or Feekes 10.5, three QoI+DMI mixtures applied at Feekes 10.5, and three treatments consisting of a QoI at Feekes 9 followed by a DMI at Feekes 10.5.1 were evaluated. Network meta-analytical models were fitted to log-transformed mean IND and DON data and estimated contrasts of log means were used to obtain estimates of mean percent controls relative to the nontreated check as measures of efficacy. Results from the meta-analyses were also used to assess the risk of DON increase in future trials. DMI at Feekes 10.5.1 were the most effective

programs against IND and DON and the least likely to increase DON in future trials. QoI-only programs increased mean DON over the nontreated checks and were the most likely to do so in future trials, particularly when applied at Feekes 10.5. The effects of QoI+DMI combinations depended on the active ingredients and whether the two were applied as a mixture at heading or sequentially. Following a Feekes 9 QoI application with a Feekes 10.5.1 application of a DMI reduced the negative effect of the QoI on DON but was not sufficient to achieve the efficacy of the Feekes 10.5.1 DMI-only treatments. Our results suggest that one must be prudent when using QoI treatments under moderate to high risk of FHB, particularly where the QoI is used without an effective DMI applied in combination or in sequence.
\end{abstract}

Fusarium head blight (FHB; also known as scab) is a major disease of wheat that has caused economic losses in several regions of the United States and throughout the world (McMullen et al. 1997, 2012). Although several species of fungi may cause FHB, Fusarium graminearum is predominant in North America (Dill-Macky 2010). Nganje et al. (2004) estimated that the total economic impact of FHB on small grain crops grown in the Northern Great Plains and Central United States from 1998 to 2000 was approximately \$2.7 billion. Although losses from reductions in grain yield (YLD) due to FHB do occur (Paul et al. 2010; Salgado et al. 2015), losses associated with reductions in grain quality are considered more devastating. These include low test weight (TW), high levels of Fusariumdamaged kernels, and contamination of grain with mycotoxins, especially deoxynivalenol (DON) and related trichothecenes produced by F. graminearum and other Fusarium spp. (Dill-Macky 2010; Shaner

${ }^{\dagger}$ Corresponding author: P. A. Paul; E-mail: paul.661@osu.edu

Funding: Salaries and research support for P. A. Paul, L. V. Madden, and F. D. DaSilva were provided by state and federal funds to the Ohio Agricultural Research and Development Center.

This is a cooperative project with the U.S. Wheat \& Barley Scab Initiative (agreements 59-0206-4-018 [The Ohio State University], 59-0206-4-006 [Cornell University], 59-0206-4-042 [Purdue University], and 59-0206-4016 [The University of Minnesota]). Any opinions, findings, conclusions, or recommendations expressed in this publication are those of the authors and do not necessarily reflect the view of the United States Department of Agriculture.

Accepted for publication 9 June 2018 .

(c) 2018 The American Phytopathological Society
2003). Grain lots with TW below and percent Fusarium-damaged kernels and DON concentration above grain quality thresholds often receive price discounts or are rejected at grain elevators (McMullen et al. 2012; Salgado et al. 2014).

Practices used to manage FHB and DON include rotation with nonhost crops and tillage (Dill-Macky 2010; Dill-Macky and Jones 2000), the use of moderately resistant cultivars (McMullen et al. 2012), and application of foliar fungicides at or shortly after anthesis (D'Angelo et al. 2014). Demethylation inhibitor (DMI) fungicides (Fungicide Resistance Action Committee [FRAC] group 3) (Anonymous 2018) have been reported to be efficacious against FHB and DON (Magan et al. 2002; Pirgozliev et al. 2002) and, among the DMI commercially available for use on wheat in the United States, metconazole (Caramba; BASF Corp., Research Triangle Park, NC), prothioconazole (Proline; Bayer CropScience, Research Triangle Park, NC), and prothioconazole + tebuconazole (Prosaro; Bayer CropScience) are more efficacious than tebuconazole (Folicur; Bayer CropScience) and propiconazole (Tilt; Syngenta Crop Protection Inc., Greensboro, NC) (Paul et al. 2008). However, the greatest and most consistent levels of FHB and DON concentration reductions are often achieved when multiple management strategies are integrated (Blandino et al. 2012; McMullen et al. 2008; Willyerd et al. 2012).

Unlike DMI, quinone outside inhibitor (QoI) fungicides (FRAC group 11) (Anonymous 2018) are generally not suggested for FHB and DON control in the United States. In addition to being relatively less efficacious than DMI against the disease (Magan et al. 2002; Pirgozliev et al. 2002), some QoI have been reported to increase DON in wheat grain, especially when applied close to anthesis (Ellner 2005; Zhang et al. 2009). However, there is conflicting information in the literature regarding DON response to QoI (Edwards et al. 2001; Pirgozliev et al. 2002; Simpson et al. 2001). For instance, Simpson et al. (2001) observed greater DON/F. culmorum biomass (DNA) ratios in 
azoxystrobin-treated plots than in plots treated with other fungicides, and concluded that this fungicide likely stimulated toxin production. Zhang et al. (2009) came to a similar conclusion about the effects of azoxystrobin on DON. Contrastingly, Pirgozliev et al. (2002) reported that azoxystrobin significantly reduced FHB and DON relative to a nontreated check and observed no evidence to support this fungicide increasing DON in harvested grain. Edwards et al. (2001) hypothesized that fungicides affected the FHB-DON relationship by altering the amount of trichothecene-producing Fusarium biomass in the grain rather than changing the rate of toxin synthesis.

Most of the published studies on the effects of QoI fungicides on DON have focused on azoxystrobin. There are fewer reports of associations between other QoI or QoI+DMI combinations and the accumulation of this toxin in harvested grain. In addition to azoxystrobin (Quadris; Syngenta Crop Protection Inc.), other QoI such as pyraclostrobin (Headline; BASF Corporation), picoxystrobin (Aproach; DuPont, Wilmington, DE), and fluoxastrobin (Evito; Arysta LifeScience, Cary, NC), as well as QoI+DMI premixes such as prothioconazole + trifloxystrobin (Stratego YLD; Bayer CropScience), propiconazole + azoxystrobin (Quilt Xcel; Syngenta Crop Protection Inc.), and metconazole + pyraclostrobin (TwinLine; BASF Corporation), are widely used on wheat in the United States, with efficacy against important diseases such as powdery mildew, Septoria leaf blight, Stagonospora leaf and glume blotch, and rust diseases (Marroni et al. 2006; Sylvester et al. 2018; Willyerd et al. 2015). Without a clear understanding of the mechanisms involved in DON response to QoI and because the reported effects of azoxystrobin vary among studies, one cannot say with certainty that all QoI-based fungicide programs are associated with increases in DON contamination of harvested grain.

In addition to disease control, many of the aforementioned QoI and QoI+DMI premixes are widely used by growers of field crops to increase YLD and promote physiological changes that improve plant health. Results from bioassays and studies under controlled conditions showed that some QoI induce physiological and developmental changes in wheat (Grossman et al. 1999; Grossmann and Retzlaff 1997; Nason et al. 2007; Wu and von Tiedemann 2001) that are believed to translate into greater stress tolerance and YLD in the field. Paul et al. (2011) reported that several QoI-based fungicides resulted in a positive YLD response in hybrid field maize, and estimated that the probability of obtaining a YLD increase great enough to offset the fungicide cost ranged from 1 to $45 \%$ at low disease levels $(<5 \%$ on the ear leaf). Willyerd et al. (2015) reported that fungicide programs that were not effective against leaf blotch diseases of wheat still had more than a $60 \%$ chance of resulting in an increase in mean YLD over the nontreated check. The possibility of a YLD benefit will continue to be an incentive for producers to apply QoI and other fungicides in field crops, particularly if grain prices are high and inexpensive (generic, off-patent) fungicides are used.

No comprehensive large-scale studies have been done to investigate the effects of QoI active ingredients (a.i.) and QoI+DMI combinations on FHB, DON, YLD, and TW in wheat. Data from years of uniform fungicide trials (UFT) conducted through the U.S. Wheat and Barley Scab Initiative were previously utilized for quantitative synthesis of the effects of DMI fungicides on FHB and DON (Paul et al. 2007, 2008), and YLD and TW (Paul et al. 2010), but no such analyses have been done for QoI in wheat. In fact, after a few years of UFT, QoI were removed from testing once they were determined to be less effective than DMI against FHB and evidence of their association with increased DON in grain was recognized. Although QoI are not recommended for application at anthesis for FHB and DON suppression, they continue to be applied from green-up or tillering (Feekes 4-5) to heading (Feekes 10.5) to manage other diseases and for the plant health potential. Consequently, questions remain regarding the effects of preanthesis applications of QoI and QoI+DMI premixes on DON. One such question relates to whether combining a DMI with a QoI will counteract any potential negative effects that QoI-only treatments may have on DON.

To address some of these questions, QoI-based fungicides were reintroduced into the UFT and evaluated across multiple states and wheat market classes from 2008 to 2013 . This generated a large body of data that was used in this investigation. These data were combined with those from previous UFT, and network meta-analyses (Madden et al. 2016) were performed to (i) quantify the effects of QoI and QoI+ DMI fungicides applied at different growth stages on FHB, DON, YLD, and TW relative to a reference set of DMI-only treatments (industry standards for FHB management) and a nontreated check; (ii) determine whether the application of premixes of QoI and DMI at anthesis, or sequential applications of a QoI followed by a DMI, counteracted any potential DON increase associated with the application of a QoI alone; and (iii) estimate the risk of DON increases following the application of QoI with and without DMI.

\section{Materials and Methods}

Database for meta-analysis. A dataset consisting of 292 UFT, supported by the U.S. Wheat and Barley Scab Initiative and conducted from 1995 to 2013, was used for this investigation. Subsets of these trials have been used previously to investigate the effects of DMI fungicides applied at anthesis on FHB and DON (through 2005) and YLD and TW (through 2007) (Paul et al. 2007, 2008, 2010). A detailed description of the UFT (plot dimensions, method of fungicide application, disease assessment, and so on) can be found in Paul et al. (2007, 2008). In brief, plots of susceptible cultivars were planted in 17 U.S. soft- and hard-wheat-producing states (Arkansas, Iowa, Illinois, Indiana, Kentucky, Louisiana, Maryland, Michigan, Minnesota, Missouri, Montana, North Dakota, New York, Ohio, South Dakota, Virginia, and Wisconsin) in a randomized complete block design with four to six replicate blocks. Plot dimensions varied among trials, ranging in width from 1.5 to $3 \mathrm{~m}$ and length from 6 to $10.7 \mathrm{~m}$.

To increase the likelihood of $F$. graminearum infection and FHB development, at least one of the following practices was employed at each location: planting wheat after an $F$. graminearum-susceptible host crop (i.e., corn or wheat), infesting the experimental area with $F$. graminearum-colonized grain spawn, inoculating wheat spikes at anthesis with a spore suspension of $F$. graminearum, and mist irrigating plots during anthesis and early grain-fill. The combination of colonized grain spawn and mist irrigation was the most widely employed (Paul et al. 2007). One or more measures of FHB (incidence, diseased head severity, or index [field severity]), DON contamination of grain, YLD, and TW were quantified as previously described (Paul et al. 2005a, 2008, 2010). Index is defined as the mean proportion of diseased spikelets per spike in all spikes assessed while severity is defined as the mean proportion of diseased spikelets in symptomatic spikes. YLD was adjusted to $13.5 \%$ moisture concentration and then converted to kilograms per hectare. TW was converted to kilograms per cubic meter. Both conversions were based on a 25-kg bushel weight for wheat.

A subset of 15 treatments, plus a nontreated check, was evaluated in this investigation. These consisted of either a DMI (tebuconazole, metconazole, propiconazole, or prothioconazole), a QoI (fluoxastrobin, trifloxystrobin, azoxystrobin, or pyraclostrobin), or some combination of the two chemistries applied as a premix, a tank mix, or sequentially (Table 1). All fungicides were applied at label-recommended rates along with a nonionic surfactant at either full flag leaf emergence (Feekes 9), boot (Feekes 10), or anthesis (Feekes 10.5.1) (Table 1). Other application parameters such as spray volume (94 to 197 liters $\mathrm{ha}^{-1}$ ) and equipment varied among trial locations. The total number of trials in which each of the selected treatments was evaluated is listed in Table 1, and the number of years, states, and trials in which a given treatment was evaluated for effect on FHB index (IND), DON, YLD, and TW is shown in Table 2.

Data analysis. Similar to what was described by Paul et al. (2008), the effects of fungicides on FHB and DON were assessed based on the magnitude and significance of mean log-transformed response ratios for each treatment relative to a reference treatment or group of treatments. Approximate mean percent control of IND and DON and $95 \%$ confidence intervals (CI) were then obtained from the mean $\log$ response ratios. A large negative log response ratio corresponds 
to a large positive percent control, which is indicative of greater efficacy (Paul et al. 2007, 2008). Percent control is the reduction in IND or DON relative to the check (i.e., the difference between the check and the treatment means, divided by the check mean). Log ratios were used directly for comparing treatments because their statistical properties are better than those of percent control (or for any ratio, in general) (Madden and Paul 2011). For YLD and TW, mean differences with the check and their 95\% CI were estimated as measure of treatment effects (Paul et al. 2010).

Network meta-analysis. A two-stage multitreatment metaanalytical approach was used to obtain estimates of treatment effect on IND, DON, YLD, and TW. In the first stage of the analysis, linear mixed models were fitted, with fungicide treatment as fixed effect and block as random effect. For each trial, IND, DON, YLD, and TW were analyzed separately, and least squares means (LS-Means) were estimated for all treatments. Residual variances were also estimated for each response in each trial and combined with the LSMeans to construct a data matrix for subsequent analysis. In stage two of the analysis, a two-way network meta-analytical model, with trial and treatment as factors, was fitted to the trial-level LS-Means or log-transformed trial-level LS-Means (from the first stage) using the GLIMMIX procedure of SAS (see below). The within-trial "sampling variances" (determined from first-stage analyses) were held fixed in the second-stage network model fitting (see Madden et al. 2016). Least-squares treatment means across all trials were determined with the lsmeans statement after the model was fitted. A second-order factor analytic structure was used for the betweentrial variance-covariance matrix (model R5 in Madden et al. 2016). More specific details of the modeling approach are presented in Madden et al. (2016), Paul et al. (2008), and Paul et al. (2010).

Log response ratios and mean differences. For IND and DON, the meta-analytical models were fitted to the trial-level log-transformed LS-Means; the fixed sampling variance for each log-transformed value was determined as presented on page 1001 of Paul et al. (2008). Mean log response ratios $(\bar{L})$ across all trials, together with their standard errors and $95 \% \mathrm{CI}$, were estimated postmodel-fitting by way of lsmestimate statements in PROC GLIMMIX. Differences between pairs of mean logs are the $\bar{L}$ values, because the log of a ratio is equal to the difference of logs. Contrasts were constructed to estimate $\bar{L}$ for each treatment relative to the nontreated check, relative to a standard set of treatments, and for specific DMI- or QoI-only treatments relative to premixes, tank mixes, or sequential applications of the two chemistries. For instance, $\bar{L}$ values relative to the check were estimated as $\bar{L}^{(C)}=\hat{\mu}_{T}-\hat{\mu}_{C}$, where $\hat{\mu}_{T}$ and $\hat{\mu}_{C}$ are the estimated mean $\ln (\mathrm{IND})$ or $\ln (\mathrm{DON})$ across trials for a treatment and the nontreated check, respectively. Note that the superscript refers to the reference treatment in the contrast (or ratio). $\bar{L}$ relative to the standard set of treatments were estimated as $\bar{L}^{(S)}=\hat{\mu}_{T}-\hat{\mu}_{S}$, where $\hat{\mu}_{S}$ is the estimated overall mean $\ln (\mathrm{IND})$ or $\ln (\mathrm{DON})$ across

Table 1. Demethylation inhibitor (D) and quinone outside inhibitor (Q) fungicide treatments evaluated for their effects on Fusarium head blight, deoxynivalenol concentration, grain yield, and test weight in wheat ${ }^{\mathrm{a}}$

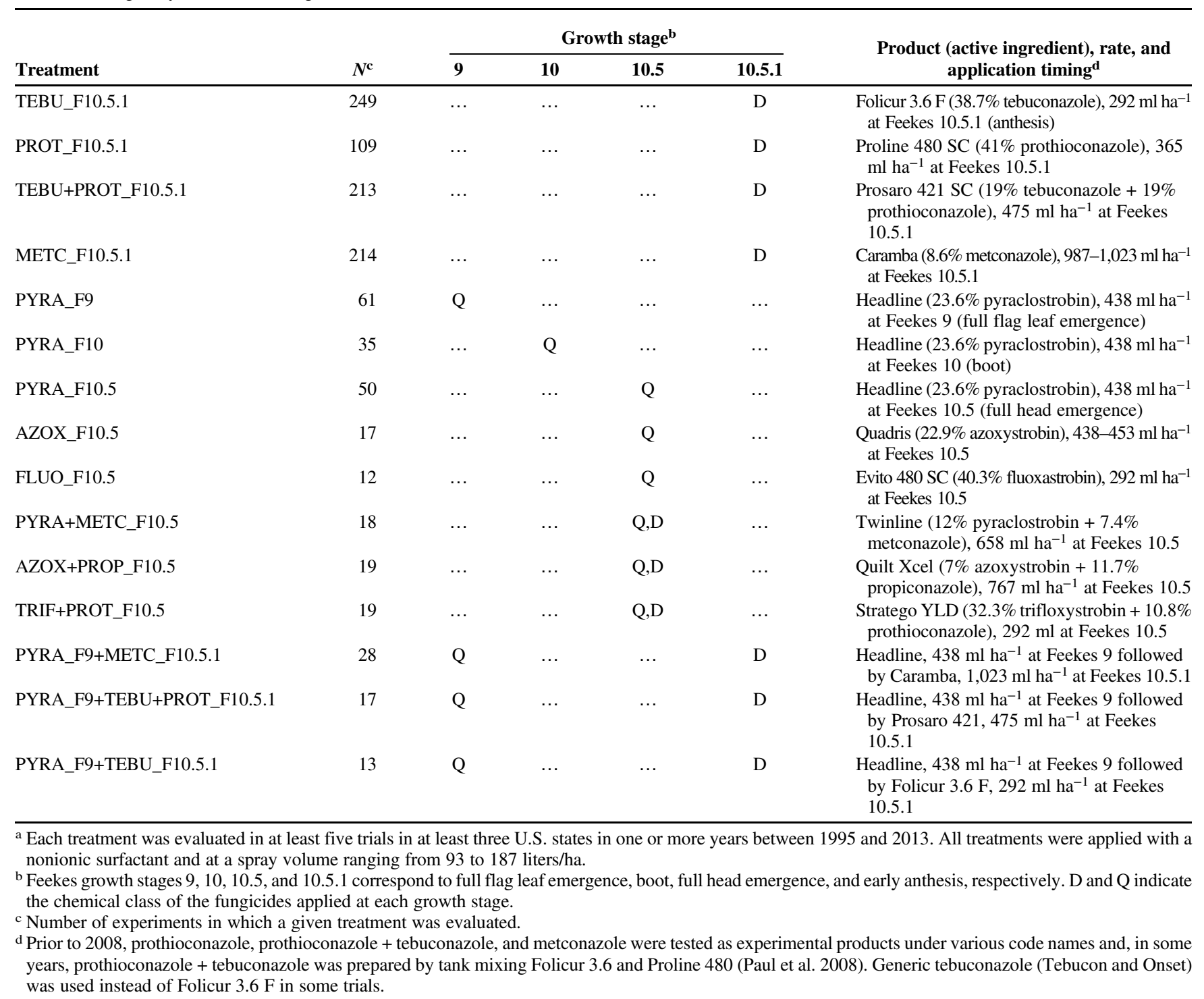


prothioconazole applied at Feekes 10.5.1 (PROT_F10.5.1), tebuconazole + prothioconazole applied at Feekes 10.5.1 (TEBU+PROT_ F10.5.1), and metconazole applied at Feekes 10.5.1 (METC_F10.5.1). These three treatments were considered the standard here because they are currently the most efficacious against FHB and DON (Paul et al. 2008).

For YLD and TW, the meta-analytical models were fitted to the original (untransformed) trial-level LS-Means from stage one of the analysis; the fixed within-trial sampling variance for each treatment was calculated based on the residual mean square, as described on page 161 of Paul et al. (2010). Overall mean differences across trials and their standard errors and $95 \% \mathrm{CI}$ were estimated post model fitting as measures of treatment effects relative to the nontreated check $\left(\bar{D}^{(C)}\right)$ and relative to the standard set of treatments $\left(\bar{D}^{(S)}\right)$. The lsmestimate statement in PROC GLIMMIX was used to obtain estimates of $\bar{D}^{(C)}=\hat{\mu}_{T}-\hat{\mu}_{C}$ and $\bar{D}^{(S)}=\hat{\mu}_{T}-\hat{\mu}_{S}$, where $\hat{\mu}_{C}, \hat{\mu}_{T}$, and $\hat{\mu}_{S}$ are estimated LS-Means YLD or TW (across trials) for the nontreated check, a treatment, and the standard set of treatments (averaged across treatments PROT_F10.5.1, TEBU+PROT_F10.5.1, and METC_F10.5.1), respectively.

Relative responses. For each treatment, approximate mean percent control $(\bar{C})$ values and their $95 \%$ CI were estimated for IND and DON from the $\bar{L}^{(C)}$ values and their $95 \%$ CIs as

$$
\bar{C}=\left[1-\exp \left(\bar{L}^{(C)}\right)\right] \times 100
$$

Similarly, approximate mean percent increase relative to the standard, $\bar{S}$, was estimated from $\bar{L}^{(S)}$ as

$$
\bar{S}=\left[\exp \left(\bar{L}^{(S)}\right)-1\right] \times 100
$$

Additional details are presented in Paul et al. (2008) and Madden and Paul (2011). These back transformations of means directly give median percentages but, because these statistics are close to the mean percentages, we generally refer to them as the latter. Similar measures of relative response were estimated for pairwise comparisons of DON between selected QoI, DMI, and QoI+DMI treatments to address questions pertaining to whether preanthesis QoI-only treatments resulted in greater DON concentrations than the nontreated check, whether QoI+DMI treatments resulted in greater
DON concentrations than DMI-only treatments, and whether sequential applications of a QoI at an early growth stage followed by a DMI-only treatment at anthesis resulted in lower DON concentrations than the early QoI-only treatments. For instance, mean $\ln (\mathrm{DON})$ was compared between the pyraclostrobin at Feekes 9 (PYRA_F9) and pyraclostrobin at Feekes 9 followed by metconazole at Feekes 10.5.1 (PYRA_F9+METC_F10.5.1) treatments (Table 1).

Prediction and risk analysis. $\bar{L}^{(C)}$ and $\bar{D}^{(C)}$ values were used along with estimates of their respective between-study standard deviation $\left(\hat{\sigma}^{(C)}\right.$; determined as presented on page 1003 of Paul et al. [2008]) from the meta-analysis to make predictions regarding efficacy and the risk of a given treatment program resulting in greater (or lower) overall mean IND, DON, YLD, or TW than some predetermined value in a new randomly selected study (done in the similar way to the studies used in this analysis). Specifically, probabilities were estimated that treatments with a significant effect on IND or DON (Table 3) will result in percent control greater than fixed values between 2 and $50 \%$ (i.e., probabilities that IND or DON will be reduced relative to the nontreated check by 2 to $50 \%)$. For instance, the probability of at least a $50 \%$ control $(\bar{C}>50 \%)$, which is equivalent to the probability that $\bar{L}^{(C)}<-0.69$, was estimated as

$$
p_{50}^{(C)}=\varnothing\left(-0.69-\bar{L}^{(C)}\right) / \hat{\sigma}^{(C)}
$$

To assess the risk of increasing DON concentration following the application of QoI-based treatments to FHB-affected plots, probabilities were also estimated that treatments with a significant effect on DON (Table 3) will result in 2 and 50\% greater mean DON than the nontreated check. For example, a DON increase of at least $25 \%$ relative to the check (i.e., probability that $\bar{C}$ is less than $-25 \%$ ), equivalent to the probability that $\bar{L}^{(C)}>0.223$, was given by

$$
p_{25}^{(C)}=\varnothing\left(\bar{L}^{(C)}-0.223\right) / \hat{\sigma}^{(C)}
$$

Probabilities of YLD increases ranging from 50 to $500 \mathrm{~kg} \mathrm{ha}^{-1}$ and increases in TW between 2 and $50 \mathrm{~kg} / \mathrm{m}^{3}$ relative to the nontreated check were also estimated. For instance, the probabilities of a $250 \mathrm{~kg} \mathrm{ha}^{-1}$ increase in YLD and a $20 \mathrm{~kg} / \mathrm{m}^{3}$ increase in TW were

\begin{tabular}{|c|c|c|c|c|c|c|c|c|c|c|c|c|}
\hline \multirow[b]{2}{*}{ Treatment $^{\mathbf{b}}$} & \multicolumn{4}{|c|}{ Number of trial years } & \multicolumn{4}{|c|}{ Number of states } & \multicolumn{4}{|c|}{ Total number of trials } \\
\hline & IND & DON & YLD & $\overline{T W}$ & IND & DON & YLD & $\overline{\text { TW }}$ & $\overline{\text { IND }}$ & DON & YLD & $\overline{T W}$ \\
\hline Check & 19 & 17 & 17 & 17 & 16 & 15 & 16 & 16 & 292 & 207 & 245 & 225 \\
\hline TEBU_F10.5.1 & 19 & 17 & 17 & 17 & 16 & 15 & 16 & 16 & 249 & 175 & 202 & 185 \\
\hline PROT_F10.5.1 & 7 & 6 & 7 & 7 & 15 & 13 & 15 & 14 & 109 & 80 & 76 & 68 \\
\hline TEBU+PROT_F10.5.1 & 12 & 12 & 12 & 12 & 15 & 15 & 16 & 16 & 213 & 153 & 196 & 184 \\
\hline METC_F10.5.1 & 13 & 13 & 13 & 13 & 15 & 15 & 16 & 16 & 214 & 154 & 193 & 186 \\
\hline PYRA_F9 & 5 & 5 & 5 & 5 & 11 & 11 & 11 & 10 & 61 & 46 & 61 & 59 \\
\hline PYRA_F10 & 3 & 3 & 3 & 3 & 7 & 7 & 7 & 7 & 35 & 30 & 34 & 33 \\
\hline PYRA_F10.5 & 4 & 4 & 4 & 4 & 9 & 9 & 9 & 9 & 50 & 38 & 50 & 48 \\
\hline AZOX_F10.5 & 1 & 1 & 1 & 1 & 8 & 7 & 8 & 7 & 17 & 10 & 17 & 16 \\
\hline FLUO_F10.5 & 1 & 1 & 1 & 1 & 6 & 5 & 6 & 5 & 12 & 5 & 12 & 11 \\
\hline PYRA+METC_F10.5 & 1 & 1 & 1 & 1 & 9 & 8 & 9 & 8 & 18 & 11 & 18 & 17 \\
\hline AZOX+PROP_F10.5 & 1 & 1 & 1 & 1 & 10 & 9 & 10 & 8 & 19 & 12 & 19 & 17 \\
\hline TRIF+PROT_F10.5 & 1 & 1 & 1 & 1 & 10 & 9 & 10 & 8 & 19 & 12 & 19 & 17 \\
\hline PYRA_F9+METC_F10.5.1 & 2 & 2 & 2 & 2 & 8 & 6 & 8 & 6 & 28 & 17 & 30 & 28 \\
\hline PYRA_F9+TEBU+PROT_F10.5.1 & 2 & 2 & 2 & 2 & 7 & 6 & 7 & 7 & 17 & 13 & 19 & 19 \\
\hline PYRA_F9+TEBU_F10.5.1 & 1 & 1 & 1 & 1 & 4 & 3 & 4 & 4 & 13 & 9 & 15 & 15 \\
\hline
\end{tabular}
estimated as

Table 2. Number of years, states, and trials in which the listed fungicide treatments were evaluated for their effect on Fusarium head blight index (IND), deoxynivalenol (DON), grain yield (YLD), and test weight (TW) in whea ${ }^{\mathrm{a}}$

${ }^{a}$ Uniform fungicide trials were conducted in 17 U.S. states (Arkansas, Iowa, Illinois, Indiana, Kentucky, Louisiana, Maryland, Michigan, Minnesota, Missouri, Montana, North Dakota, New York, Ohio, South Dakota, Virginia, and Wisconsin) from 1995 through 2013, with varying number of states and trials per year. b Treatments consisted of demethylation inhibitor fungicides tebuconazole (TEBU), prothioconazole (PROT), propiconazole (PROP), or metconazole (METC) or quinone outside inhibitor fungicides pyraclostrobin (PYRA), azoxystrobin (AZOX), fluoxastrobin (FLUO), or trifloxystrobin (TRIF) applied at labelrecommended rates as either solo active ingredients or premixes, or sequentially during flag leaf emergence (Feekes growth stage 8-9, abbreviated as F9), at boot (Feekes 10; F10), at full head emergence (Feekes 10.5; F10.5), or at anthesis (Feekes 10.5.1; F10.5.1). 


$$
p_{250}^{(C)}=\varnothing\left(\bar{D}^{(C)}-250\right) / \hat{\sigma}^{(C)}
$$

and

$$
p_{12}^{(C)}=\varnothing\left(\bar{D}^{(C)}-20\right) / \hat{\sigma}^{(C)},
$$

respectively. In all cases, $\varnothing(\bullet)$ is the cumulative standard-normal function (Paul et al. 2008, 2010).

\section{Results}

Mean IND, DON, YLD, and TW. The distributions of LS-Means for IND, DON, YLD, and TW across trials for each of the 15 tested fungicide treatments and the nontreated check are shown in Figure 1. As expected, for all four responses, treatment means varied among trials, as indicated by the size of the boxes and spread of the data points around the overall means (Fig. 1, broken lines within the boxes). For IND (Fig. 1A) and DON (Fig. 1B), the distributions were right-skewed, with the majority of the values between 0 and $25 \%$ for IND and 0 and $10 \mathrm{ppm}$ for DON. The interquartile ranges (IQR) (difference between the 25th and 75th percentiles of the data; that is, the difference between the upper and lower edges of the boxes) for both measures of FHB varied considerably among treatments, with those consisting of a Feekes 10.5.1 (anthesis) application of a DMI fungicide or a Feekes 9 application of a QoI followed by an anthesis application of a DMI generally having narrower IQR (indicative of relatively less variable responses among trials) than QoI-only treatments or premixes of the two chemistries (Fig. 1A and B). The skewness of the IND and DON means across trials is further support for the use of log-transformation of the within-trial treatment means (Schabenberger and Pierce 2002), although the transformation was primarily chosen to directly determine log response ratios (Madden and Paul 2011).

The distributions of mean YLD (Fig. 1C) and TW (Fig. 1D) were generally more symmetrical than those of mean IND and DON, with the majority of YLD values between 2.5 and 5.5 metric tons ha ${ }^{-1}$ and TW values between 6.5 and $7.5 \mathrm{~kg} / \mathrm{m}^{3}$. Trends in terms of differences in the IQR among treatment subgroups (QoI, DMI, or QoI+DMI) were less clear-cut for YLD and TW than they were for IND and
DON (Fig. 1C and D). However, there was still some evidence of greater variability (wider IQR) in mean YLD for treatments that consisted of a premix of a DMI and a QoI than those consisting of a QoI- or DMI-only application or sequential applications of the two chemistries.

Log response ratio and percent control of IND and DON relative to the nontreated check. Based on results from the metaanalysis, the estimated effect sizes $\left(\bar{L}^{(C)}\right)$ were negative and significantly different from zero for IND for all treatments that included a DMI fungicide application at anthesis $(P \leq 0.05)$, regardless of whether they consisted of the DMI alone or applied sequentially following a QoI (Table 3). The $\bar{L}^{(C)}$ values for those treatments ranged from -0.74 to -0.38 , which corresponded to overall mean percent control of IND relative to the nontreated check $(\bar{C})$ between 31.2 and $52.2 \%$ (Table 3 ). The two greatest percent controls were for metconazole at anthesis (METC_F10.5.1) and tebuconazole + prothioconazole at anthesis (TEBU+PROT_F10.5.1). $\bar{L}^{(C)}$ was also negative for all but one preanthesis QoI treatment applied alone (azoxystrobin at heading [AZOX_F10.5]). However, the effect sizes for preanthesis treatments were only significantly different from zero for pyraclostrobin at boot (PYRA_F10), pyraclostrobin at heading (PYRA_F10.5), pyraclostrobin + metconazole at heading (PYRA+METC_F10.5), and trifloxystrobin + prothioconazole at heading (TRIF+PROT_ F10.5), with $\bar{C}$ values (11.2 to $21.8 \%$ ) that were considerably lower than those observed for treatments that included an anthesis DMI application (Table 3).

The application of a DMI fungicide at anthesis or a QoI fungicide early followed by a DMI at anthesis also reduced DON relative to the nontreated check (Table 3 ). The estimated $\bar{L}^{(C)}$ values were negative, ranging from -0.55 to -0.10 , and significantly different from zero $(P<0.05)$ for all but one of the treatments that included an anthesis application (PYRA_F9+TEBU_F10.5.1). The largest percent controls were for a single application at anthesis for three different DMI (TEBU+PROT_F10.5.1, PROT_F10.5.1, and METC_F10.5.1) as well as the standard (the average of the three). The statistically significant treatments with an anthesis DMI application resulted in DON reductions ranging from 20.1 to $45.5 \%$. Contrary to what was

Table 3. Estimated mean log response ratios and corresponding mean percent control of Fusarium head blight (FHB) index and deoxynivalenol (DON) relative to

\begin{tabular}{|c|c|c|c|c|c|c|c|c|}
\hline \multirow[b]{2}{*}{ Treatment $^{\mathbf{b}}$} & \multicolumn{4}{|c|}{ FHB index } & \multicolumn{4}{|c|}{ DON } \\
\hline & $\overline{\boldsymbol{L}}^{(\boldsymbol{C})}(\boldsymbol{S E})$ & $P$ & $\hat{\sigma}_{L}^{2}$ & $\overline{\boldsymbol{C}}(\boldsymbol{C I})$ & $\overline{\boldsymbol{L}}^{(\boldsymbol{C})}(\boldsymbol{S} \boldsymbol{E})$ & $P$ & $\hat{\sigma}_{L}^{2}$ & $\overline{\boldsymbol{C}}(\boldsymbol{C I})$ \\
\hline TEBU_F10.5.1 & $-0.51(0.030)$ & $<0.001$ & 0.18 & $39.6(36.0 ; 43.1)$ & $-0.22(0.021)$ & $<0.001$ & 0.04 & $20.1(16.6 ; 23.4)$ \\
\hline PROT_F10.5.1 & $-0.69(0.045)$ & $<0.001$ & 0.22 & $49.9(45.3 ; 54.1)$ & $-0.52(0.039)$ & $<0.001$ & 0.12 & $40.3(35.6 ; 44.6)$ \\
\hline TEBU+PROT_F10.5.1 & $-0.72(0.039)$ & $<0.001$ & 0.23 & $51.5(47.6 ; 55.1)$ & $-0.48(0.031)$ & $<0.001$ & 0.10 & $38.2(34.3 ; 41.8)$ \\
\hline METC_F10.5.1 & $-0.74(0.038)$ & $<0.001$ & 0.20 & $52.2(48.6 ; 55.6)$ & $-0.55(0.034)$ & $<0.001$ & 0.12 & $45.5(38.5 ; 46.2)$ \\
\hline Standard & $-0.72(0.035)$ & $<0.001$ & 0.21 & $51.2(47.8 ; 54.4)$ & $-0.52(0.030)$ & $<0.001$ & 0.11 & $40.3(36.7 ; 43.8)$ \\
\hline PYRA_F9c & $-0.06(0.036)$ & 0.111 & 0.04 & $5.5(-1.3 ; 11.9)$ & $0.06(0.030)$ & 0.062 & 0.02 & $-5.9(-12.4 ; 0.3)$ \\
\hline PYRA_F10 & $-0.12(0.050)$ & 0.009 & 0.03 & $11.2(2.9 ; 18.9)$ & $0.14(0.039)$ & $<0.001$ & 0.03 & $-15.3(-24.6 ;-6.7)$ \\
\hline PYRA_F10.5 ${ }^{\mathrm{c}}$ & $-0.22(0.040)$ & $<0.001$ & 0.04 & $21.8(15.4 ; 27.7)$ & $0.16(0.031)$ & $<0.001$ & 0.02 & $-17.8(-25.2 ;-10.9)$ \\
\hline AZOX_F10.5 & $0.16(0.162)$ & 0.130 & 0.64 & $-17.6(-44.9 ; 4.63)$ & $0.15(0.059)$ & 0.012 & 0.02 & $-16.1(-30.3 ;-3.4)$ \\
\hline FLUO_F10.5 & $-0.05(0.093)$ & 0.574 & 0.12 & $5.1(-13.8 ; 20.9)$ & $0.12(0.091)$ & 0.175 & 0.21 & $-13.1(-35.1 ; 5.3)$ \\
\hline PYRA+METC_F10.5 & $-0.17(0.073)$ & 0.020 & 0.16 & $15.7(2.7 ; 27.0)$ & $0.02(0.061)$ & 0.768 & 0.05 & $-1.8(-14.8 ; 9.7)$ \\
\hline AZOX+PROP_F10.5 & $-0.11(0.074)$ & 0.146 & 0.11 & $10.2(-3.8 ; 22.4)$ & $0.14(0.056)$ & 0.013 & 0.03 & $-15.0(-28.5 ;-3.0)$ \\
\hline TRIF+PROT_F10.5 & $-0.19(0.081)$ & 0.019 & 0.22 & $17.4(3.1 ; 29.5)$ & $-0.01(0.056)$ & 0.829 & 0.03 & $1.3(-11.1 ; 12.3)$ \\
\hline PYRA_F9+METC_F10.5.1 & $-0.54(0.080)$ & $<0.001$ & 0.22 & $41.8(31.9 ; 50.2)$ & $-0.34(0.060)$ & $<0.001$ & 0.04 & $26.6(19.6 ; 36.6)$ \\
\hline PYRA_F9 +TEBU+PROT_F10.5.1 & $-0.61(0.104)$ & $<0.001$ & 0.14 & $45.7(33.5 ; 55.7)$ & $-0.36(0.076)$ & $<0.001$ & 0.11 & $30.5(19.3 ; 40.1)$ \\
\hline PYRA_F9+TEBU_F10.5.1 & $-0.38(0.120)$ & 0.002 & 0.27 & $31.2(13.1 ; 45.6)$ & $-0.10(0.074)$ & 0.198 & 0.10 & $9.1(-5.1 ; 21.5)$ \\
\hline
\end{tabular}
a nontreated check from network meta-analyses of the effect of fungicide treatments on FHB index and DON in wheat ${ }^{\mathrm{a}}$

${ }^{\mathrm{a}} \log$ response ratios relative to a nontreated check $\left(\bar{L}^{(C)}\right)$ and their corresponding standard errors (SE), levels of significance $(P)$, between-study variances $\left(\hat{\sigma}_{L}^{2}\right)$, percent control $(\bar{C})$, and lower and upper limits of the $95 \%$ confidence intervals $(C I)$ around $\bar{C}$.

${ }^{\mathrm{b}}$ Treatments consisted of demethylation inhibitor fungicides tebuconazole (TEBU), prothioconazole (PROT), propiconazole (PROP), or metconazole (METC) or quinone outside inhibitor fungicides pyraclostrobin (PYRA), azoxystrobin (AZOX), fluoxastrobin (FLUO), or trifloxystrobin (TRIF) applied at labelrecommended rates as either solo active ingredients or premixes, or sequentially during flag leaf emergence (Feekes growth stage 8-9, abbreviated as F9), at boot (Feekes 10; F10), at full head emergence (Feekes 10.5; F10.5), or at anthesis (Feekes 10.5.1; F10.5.1). Standard represents the mean of PROT_F10.5.1, TEBU+PROT_F10.5.1, and METC_F10.5.1.

${ }^{c}$ Positive $\bar{L}^{(C)}$ value and correspondingly, negative $\bar{C}$ values signify significant increases in mean deoxynivalenol relative to the nontreated check in response to each of the indicated treatments $(P<0.05)$. 
observed for IND, the log-response ratios (effect sizes) for DON were positive for all, and significantly different from zero for three of the five preanthesis QoI-only treatments and for one of the three QoI+DMI premixed treatments (Table 3 ). Positive $\bar{L}$ correspond to negative percent control $(\bar{C})$, meaning an increase in mean DON relative to the check. For the statistically significant treatments, the corresponding DON increases relative to the nontreated check were 15.0, 15.3, 16.1, and $17.8 \%$ for AZOX+PROP_F10.5, PYRA_F10, AZOX_F10.5, and PYRA_F10.5, respectively (Table 3). The earliest tested QoI treatment, PYRA_F9, had a marginal effect on DON $(P=0.06)$, with a $5.9 \%$ increase relative to the nontreated check.

Contrasts were constructed to determine whether a Feekes 9 application of the QoI PYRA (PYRA_F9) followed by an anthesis application of a DMI (TEBU_F10.5.1, METC_F10.5.1, or TEBU+PROT_F10.5.1) resulted in greater mean DON than an anthesis-only application of the same DMI (Table 4). The treatment that consisted of PYRA_ F9 followed by METC_F10.5.1 had significantly $(P<0.05)$ greater mean DON than METC_F10.5.1 ( $\bar{C}=-24 \%$; that is, $24 \%$ more $)$ but those consisting of PYRA_F9 followed by TEBU+PROT_F10.5.1 or TEBU_F10.5.1 resulted in numerically $(\bar{C}=-14$ to $-13 \%)$ but not significantly $(P>0.08)$ greater DON than TEBU+PROT_F10.5.1 or TEBU_F10.5.1, respectively. Sequential application treatments (PYRA_F9 followed by METC_F10.5.1, TEBU+PROT_F10.5.1, or TEBU_F10.5.1) resulted in significantly lower mean DON than the Feekes 9 QoI-only treatment (PYRA_F9) $(\bar{C}$ values of 32.6, 34.3 , and $14.2 \%$, respectively) (Table 4 ).

Log response ratio and percent change in IND and DON relative to the standard. LS-Means for $\ln (\mathrm{IND})$ and $\ln (\mathrm{DON})$ averaged across TEBU+PROT_F10.5.1, PROT_F10.5.1, or METC_F10.5.1 were used as the standard reference (a type of positive control; the best overall known group of treatments for IND and DON management) against which other treatments were compared. The estimated effect sizes $\left(\bar{L}^{(S)}\right)$ were all positive for both IND and DON (Table 5), indicating that all treatments resulted in numerically greater mean disease and toxin concentrations than the standard (i.e., that the percent increase relative to the standard, $\bar{S}$, was positive). For IND, $\bar{L}^{(S)}$ was significantly different from zero $(P<0.05)$ for all but the treatment that consisted of a Feekes 9 application of PYRA followed by an anthesis application of TEBU+PROT. $\bar{S}$ ranged from 11.3 to $141 \%$, with treatments consisting of preanthesis applications of a
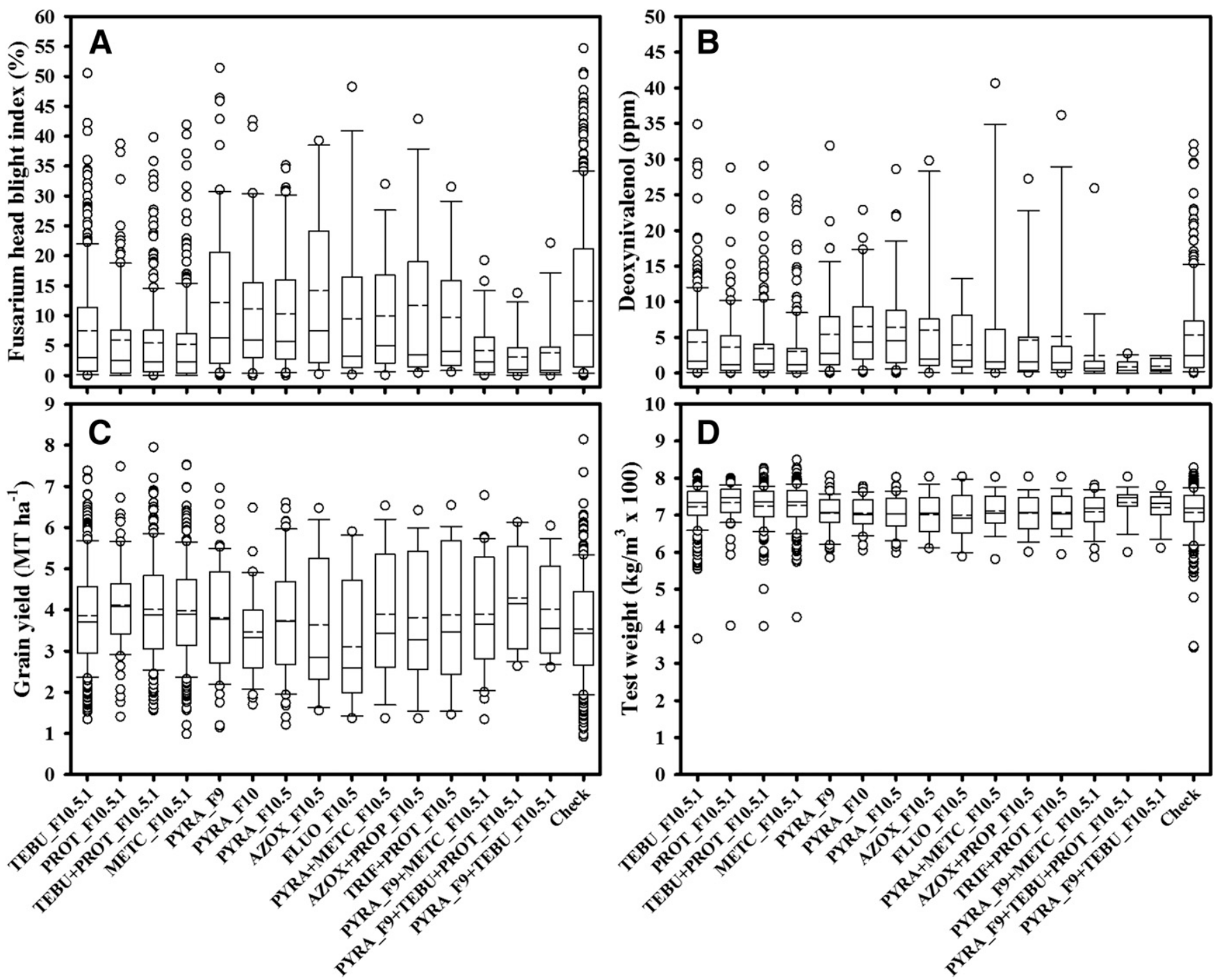

Fig. 1. Box plot showing A, the distribution of least square mean Fusarium head blight index; B, deoxynivalenol content of harvested grain; C, grain yield (metric tons [MT]); and D, test weight for different fungicide treatments. Treatments consisted of demethylation inhibitor fungicides tebuconazole (TEBU), prothioconazole (PROT), propiconazole (PROP), or metconazole (METC) or quinone outside inhibitor fungicides pyraclostrobin (PYRA), azoxystrobin (AZOX), fluoxastrobin (FLUO), or trifloxystrobin (TRIF) applied at labelrecommended rates as either solo active ingredients or premixes, or sequentially during flag leaf emergence (Feekes growth stage 8-9, abbreviated as F9), at boot (Feekes 10; F10), at full head emergence (Feekes 10.5; F10.5), or at anthesis (Feekes 10.5.1; F10.5.1). Broken and solid lines within each box represent means and medians, respectively, while the top and bottom lines of the box represent the 75th and 25th percentiles of the data, respectively. Vertical bars extending beyond the boxes represent the 10th and 90th percentiles, while circles represent outliers. 
QoI alone generally having greater $\bar{S}$ values (60.3 to $141 \%$ ) than those that included an anthesis application of a DMI (11.3 to $40.9 \%$ ). For DON, $\bar{L}^{(S)}$ values ranged from 0.153 to 0.681 , corresponding to increases of 16.6 to $97.6 \%$ over the standard. Again, the preanthesis QoI-only treatments had the highest $\bar{S}$ values (77.5 to $97.6 \%$ ), whereas treatments that included a DMI application at anthesis had the lowest (16.6 to 52.3\%) (Table 5).

Mean difference in YLD and TW relative to the nontreated check. All fungicide treatments had a significant effect on YLD, based on effect size from the meta-analysis (Table 6). The overall estimated mean YLD difference relative to the nontreated check $\left(\bar{D}^{(C)}\right)$ was significantly different from zero, and positive, for all treatments $(P<0.05) . \bar{D}^{(C)}$ ranged from 274 to 432,180 to 275,174 to 333 , and 435 to $504 \mathrm{~kg} / \mathrm{h}$ a for DMI fungicides applied alone (at anthesis), QoI fungicides applied alone (before anthesis), QoI+DMI applied as a premix, and QoI applied sequentially with DMI, respectively (Table 6). The sequential application treatments had the numerically greatest percent increases.
For all fungicide treatments, except PYRA_F10, AZOX_F10.5, and fluoxastrobin at heading (FLUO_F10.5), the estimated mean difference in TW relative to the nontreated check $\left(\bar{D}^{(C)}\right)$ was significantly different from zero $(P<0.05)$ and positive, based on results from the meta-analysis (Table 6). $\bar{D}^{(C)}$ ranged from 9.6 to $16.2 \mathrm{~kg} / \mathrm{m}^{3}$ for DMI fungicides applied alone at anthesis, compared with 0.9 to $4.1 \mathrm{~kg} / \mathrm{m}^{3}$ for QoI fungicides applied alone before anthesis, 4.6 to $10.5 \mathrm{~kg} / \mathrm{m}^{3}$ for QoI applied as a premix with a DMI, and 11.2 to $14.9 \mathrm{~kg} / \mathrm{m}^{3}$ for treatments consisting of a QoI applied at Feekes 9 followed by a DMI at anthesis (Table 6).

Mean difference in YLD and TW relative to the standard. Relative to the standard, all treatments, except for those consisting of an anthesis application of a DMI, resulted in significantly lower mean YLD (negative effects sizes, $\bar{D}^{(S)}$, with $P<0.05$ ) (Table 7). $\bar{D}^{(S)}$ values were positive for treatments with sequential applications and, for this subgroup only, significantly different from zero when TEBU+PROT was applied after PYRA in the sequence. For treatments consisting of the application of a QoI alone or QoI+DMI

Table 4. Log response ratios (effect sizes), percent change, and corresponding statistics for the effects of quinone outside inhibitor (QoI) + demethylation inhibitor (DMI) sequential treatments relative to solo QoI- or DMI-only treatments on deoxynivalenol (DON) contamination of wheat grain from network meta-analyses of the effect of fungicide treatments on DON

\begin{tabular}{|c|c|c|c|c|c|c|c|c|}
\hline \multirow[b]{2}{*}{ Contrasts $^{c}$} & \multicolumn{5}{|c|}{ Effect size $^{\mathbf{a}}$} & \multicolumn{3}{|c|}{ Percent change $^{b}$} \\
\hline & $\bar{L}$ & $\operatorname{se}(\bar{L})$ & $C l_{L}$ & $C l_{U}$ & $P$ & $\overline{\boldsymbol{C}}$ & $C l_{L}$ & $C L_{U}$ \\
\hline $\begin{array}{l}\text { PYRA_F9+METC_F10.5.1 versus METC_ } \\
\text { F10.5.1 }\end{array}$ & 0.22 & 0.062 & 0.34 & 0.09 & $<0.001$ & -24.1 & -40.3 & -9.8 \\
\hline $\begin{array}{l}\text { PYRA_F9+TEBU+PROT_F10.5.1 versus } \\
\text { TEBU+PROT_F10.5.1 }{ }^{\mathrm{d}}\end{array}$ & 0.12 & 0.073 & 0.26 & -0.02 & 0.106 & -12.5 & -29.7 & 2.5 \\
\hline $\begin{array}{l}\text { PYRA_F9+TEBU_F10.5.1 versus TEBU_ } \\
\text { F10.5.1 }\end{array}$ & 0.13 & 0.074 & 0.27 & -0.02 & 0.083 & -13.7 & -31.4 & 1.7 \\
\hline $\begin{array}{l}\text { PYRA_F9+METC_F10.5.1 versus PYRA_ } \\
\text { F9 }\end{array}$ & -0.39 & 0.065 & -0.52 & -0.27 & $<0.001$ & 32.6 & 40.6 & 23.5 \\
\hline $\begin{array}{l}\text { PYRA_F9+TEBU+PROT_F10.5.1 versus } \\
\text { PYRA_F9 }\end{array}$ & -0.42 & 0.081 & -0.58 & -0.26 & $<0.001$ & 34.3 & 43.9 & 23.1 \\
\hline PYRA_F9+TEBU_F10.5.1 versus PYRA_F9 & -0.15 & 0.078 & -0.31 & 0.00 & 0.050 & 14.2 & 26.3 & -0.01 \\
\hline
\end{tabular}

a $\bar{L}=$ mean log of the response ratio between pairs of treatments, $\operatorname{se}(\bar{L})=$ standard error of $\bar{L}, C I_{U}$ and $C I_{L}=$ upper and lower limits of the $95 \%$ confidence interval $(C I)$ around $\bar{L}$, and $P=$ significance level.

b $\bar{C}=$ mean percent change estimated from $\bar{L}$ as $\bar{C}=[1-\exp (\bar{L})] \times 100$, and $C I_{U}$ and $C I_{L}=$ upper and lower limits of the $95 \% C I$ around $\bar{C}$.

$\mathrm{c}$ Treatments consisted of DMI fungicides tebuconazole (TEBU), prothioconazole (PROT), or metconazole (METC) or the QoI fungicide pyraclostrobin (PYRA) applied at label-recommended rates either alone or sequentially during flag leaf emergence (Feekes growth stage 8-9, abbreviated as F9) or at anthesis (Feekes 10.5.1; F10.5.1). For all contrasts, the solo DMI treatments at anthesis or QoI treatments at Feekes 9 were the references against which the sequential application treatments were compared.

${ }^{\mathrm{d}}$ Positive $\bar{L}$ values and correspondingly negative $\bar{C}$ values signify increases in mean DON relative to the reference treatment with each of the indicated treatment.

Table 5. Estimated mean log response ratios and corresponding mean percent increase in Fusarium head blight (FHB) index and deoxynivalenol (DON) relative to a standard set of treatments from network meta-analyses of the effect of fungicide treatments on FHB index and DON in wheat ${ }^{\mathrm{a}}$

\begin{tabular}{|c|c|c|c|c|c|c|}
\hline \multirow[b]{2}{*}{ Treatment $^{\mathbf{b}}$} & \multicolumn{3}{|c|}{ FHB index } & \multicolumn{3}{|c|}{ Deoxynivalenol } \\
\hline & $\overline{\boldsymbol{L}}^{(\boldsymbol{S})}(\boldsymbol{S} \boldsymbol{E})$ & $P$ & $\overline{\boldsymbol{S}}(\boldsymbol{C I})$ & $\overline{\boldsymbol{L}}^{(\boldsymbol{S})}(\boldsymbol{S} \boldsymbol{E})$ & $P$ & $\overline{\boldsymbol{S}}(\boldsymbol{C I})$ \\
\hline TEBU_F10.5.1 & $0.21(0.024)$ & $<0.001$ & $23.8(18.0 ; 29.7)$ & $0.30(0.023)$ & $<0.001$ & $34.0(28.0 ; 40.3)$ \\
\hline PYRA_F9 & $0.66(0.043)$ & $<0.001$ & $93.7(77.9 ; 110.9)$ & $0.57(0.041)$ & $<0.001$ & $77.5(63.8 ; 92.3)$ \\
\hline PYRA_F10 & $0.60(0.054)$ & $<0.001$ & $81.9(63.2 ; 102.0)$ & $0.66(0.011)$ & $<0.001$ & $93.3(74.7 ; 113.8)$ \\
\hline PYRA_F10.5 & $0.47(0.049)$ & $<0.001$ & $60.3(45.7 ; 76.4)$ & $0.68(0.040)$ & $<0.001$ & $97.6(82.5 ; 113.8)$ \\
\hline AZOX_F10.5 & $0.88(0.118)$ & $<0.001$ & $141.0(91.3 ; 203.5)$ & $0.67(0.065)$ & $<0.001$ & $94.6(71.4 ; 120.9)$ \\
\hline FLUO_F10.5 & $0.67(0.102)$ & $<0.001$ & $94.6(59.3 ; 137.6)$ & $0.64(0.098)$ & $<0.001$ & $89.6(56.5 ; 129.6)$ \\
\hline PYRA+METC_F10.5 & $0.17(0.076)$ & 0.020 & $19.4(2.9 ; 38.3)$ & $0.54(0.064)$ & $<0.001$ & $70.7(50.4 ; 93.7)$ \\
\hline AZOX+PROP_F10.5 & $0.61(0.084)$ & $<0.001$ & $84.0(56.1 ; 116.9)$ & $0.66(0.063)$ & $<0.001$ & $92.8(70.6 ; 117.9)$ \\
\hline TRIF+PROP_F10.5 & $0.53(0.090)$ & $<0.001$ & $69.4(41.9 ; 102.1)$ & $0.50(0.065)$ & $<0.001$ & $65.5(45.7 ; 88.0)$ \\
\hline PYRA_F9+METC_F10.5.1 & $0.18(0.076)$ & 0.020 & $19.4(2.9 ; 38.5)$ & $0.18(0.061)$ & 0.003 & $19.6(6.2 ; 34.8)$ \\
\hline PYRA_F9 +TEBU+PROT_F10.5.1 & $0.11(0.102)$ & 0.296 & $11.3(8.9 ; 36.1)$ & $0.15(0.072)$ & 0.034 & $16.6(1.1 ; 34.3)$ \\
\hline PYRA_F9+TEBU_F10.5.1 & $0.34(0.117)$ & 0.003 & $40.9(12.1 ; 77.2)$ & $0.42(0.074)$ & $<0.001$ & $52.3(31.8 ; 76.1)$ \\
\hline
\end{tabular}

${ }^{a}$ Log response ratios relative to a standard set of treatments $\left(\bar{L}^{(S)}\right)$ and their corresponding standard errors $(\mathrm{SE})$, levels of significance $(P)$, percent increase $(\bar{S})$, and lower and upper limits of the $95 \%$ confidence intervals $(C I)$ around $\bar{S}$. The standard set of treatments represents the mean of PROT_F10.5.1, TEBU+PROT_ F10.5.1, and METC_F10.5.1.

$\mathrm{b}$ Treatments consisted of demethylation inhibitor fungicides tebuconazole (TEBU), prothioconazole (PROT), propiconazole (PROP), or metconazole (METC) or quinone outside inhibitor fungicides pyraclostrobin (PYRA), azoxystrobin (AZOX), fluoxastrobin (FLUO), or trifloxystrobin (TRIF) applied at label-recommended rates as either solo active ingredients or premixes, or sequentially during flag leaf emergence (Feekes growth stage 8-9, abbreviated as F9), at boot (Feekes 10; F10), at full head emergence (Feekes 10.5; F10.5), or at anthesis (Feekes 10.5.1; F10.5.1). 
premixes, mean YLD was 132 to 227 and 75 to $234 \mathrm{~kg} \mathrm{ha}^{-1}$ lower, respectively, than the standard. $\bar{D}^{(S)}$ values were also negative for TW and significantly different from zero $(P<0.05)$ (Table 7$)$ for all but one treatment (sequential application of PYRA and TEBU+PROT), indicating lower mean TW compared with the standard. QoI-only and QoI+DMI premix treatments again suffered the greatest reductions in TW relative to the standard, with $\bar{D}^{(S)}$ values between -14.9 and $-5.3 \mathrm{~km} / \mathrm{m}^{3}$ (Table 7).

Prediction and risk analysis. IND. Estimated probabilities of obtaining a 2 to $50 \%$ reduction in mean IND relative to the mean of a nontreated check in a new randomly selected trial are shown in Figure 2. Across all projected levels of control, the standard (used here as a measure of the mean efficacy of PROT_F10.5.1,
TEBU+PROT_F10.5.1, and METC_F10.5.1) had the highest estimated probabilities, with an $83 \%$ chance of resulting in at least $25 \%$ control $\left(p_{25}^{(C)}=0.83\right)$ and a $54 \%$ chance of at least $50 \%$ control $\left(p_{50}^{(C)}=0.54\right)$ of IND relative to the nontreated check. In other words, the probability was 0.83 that the percent reduction in IND compared with the control was $25 \%$ or more, or the probability was 0.54 that the percent reduction in IND was $50 \%$ or more. All of the tested QoI and QoI+DMI treatments that had a significant effect on IND (Table 3 ) had greater than a 0.50 probability of reducing mean IND by at least $10 \%$ in a new trial. PYRA_F10.5, in particular, had the highest $p_{10}^{(C)}$ value (0.76) of the QoI-only treatments, and a higher $p_{10}^{(C)}$ value then several of the QoI+DMI combination treatments (Fig. 2). However, preanthesis QoI-only and QoI+DMI premixes were the least

Table 6. Estimated mean difference in grain yield and test weight relative to a nontreated check and corresponding statistics from network meta-analyses of the effects of fungicide treatments on wheat grain yield and test weight in Fusarium head blight affected plots ${ }^{\mathrm{a}}$

\begin{tabular}{|c|c|c|c|c|c|c|c|c|c|c|}
\hline \multirow[b]{2}{*}{ Treatment $^{\mathbf{b}}$} & \multicolumn{5}{|c|}{ Grain yield } & \multicolumn{5}{|c|}{ Test weight } \\
\hline & $\bar{D}^{(C)}(\mathrm{SE})$ & $C I$ & $P$ & $\hat{\sigma}_{D}^{2}\left(\times 10^{3}\right)$ & $p_{250}$ & $\bar{D}^{(C)}(\mathrm{SE})$ & $C I$ & $P$ & $\hat{\sigma}_{D}^{2}$ & $p_{12}$ \\
\hline TEBU_F10.5.1 & $274(19)$ & $237 ; 310$ & $<0.001$ & 35 & 0.55 & $9.6(0.9)$ & $7.9 ; 11.4$ & $<0.001$ & 96 & 0.40 \\
\hline PROT_F10.5.1 & $393(30)$ & $333 ; 452$ & $<0.001$ & 67 & 0.71 & $15.3(1.5)$ & $12.4 ; 18.1$ & $<0.001$ & 218 & 0.59 \\
\hline TEBU+PROT_F10.5.1 & $432(22)$ & $388 ; 476$ & $<0.001$ & 63 & 0.76 & $16.0(1.2)$ & $13.6 ; 18.4$ & $<0.001$ & 206 & 0.61 \\
\hline METC_F10.5.1 & $399(22)$ & $355 ; 441$ & $<0.001$ & 58 & 0.73 & $16.2(1.6)$ & $12.9 ; 19.4$ & $<0.001$ & 455 & 0.58 \\
\hline Standard ${ }^{c}$ & $408(21)$ & $367 ; 448$ & $<0.001$ & 64 & 0.73 & $15.8(1.3)$ & $13.3 ; 18.4$ & $<0.001$ & 290 & 0.59 \\
\hline PYRA_F9 & $221(50)$ & $123 ; 319$ & $<0.001$ & 247 & 0.48 & $3.7(1.3)$ & $1.1 ; 6.3$ & 0.005 & 46 & 0.11 \\
\hline PYRA_F10 & $180(51)$ & $80 ; 280$ & $<0.001$ & 184 & 0.44 & $2.3(1.8)$ & $-1.3 ; 5.9$ & 0.216 & 52 & 0.09 \\
\hline PYRA_F10.5 & $275(48)$ & $180 ; 369$ & $<0.001$ & 196 & 0.52 & $4.1(1.4)$ & $1.3 ; 6.8$ & 0.004 & 46 & 0.12 \\
\hline AZOX_F10.5 & $188(73)$ & $45 ; 330$ & 0.001 & 293 & 0.45 & $0.9(2.2)$ & $-3.3 ; 5.1$ & 0.673 & 66 & 0.09 \\
\hline FLUO_F10.5 & $236(80)$ & $78 ; 394$ & 0.003 & 326 & 0.49 & $2.2(2.7)$ & $-3.1 ; 7.5$ & 0.418 & 57 & 0.10 \\
\hline PYRA+METC_F10.5 & $333(58)$ & $218 ; 448$ & $<0.001$ & 148 & 0.59 & $10.5(2.0)$ & $6.5 ; 14.5$ & $<0.001$ & 139 & 0.45 \\
\hline AZOX+PROP_F10.5 & $174(67)$ & $42 ; 306$ & 0.010 & 249 & 0.44 & $4.6(2.0)$ & $0.6 ; 8.6$ & 0.023 & 70 & 0.19 \\
\hline TRIF+PROT_F10.5 & $226(74)$ & $81 ; 372$ & 0.002 & 317 & 0.48 & $7.3(2.0)$ & $3.4 ; 11.3$ & $<0.001$ & 100 & 0.32 \\
\hline PYRA_F9+METC_F10.5.1 & $435(39)$ & $359 ; 511$ & $<0.001$ & 48 & 0.80 & $11.2(1.8)$ & $7.7 ; 14.8$ & $<0.001$ & 175 & 0.48 \\
\hline PYRA_F9 +TEBU+PROT_F10.5.1 & $504(49)$ & $409 ; 599$ & $<0.001$ & 61 & 0.85 & $14.9(2.2)$ & $10.7 ; 19.1$ & $<0.001$ & 292 & 0.57 \\
\hline PYRA_F9+TEBU_F10.5.1 & $467(52)$ & $366 ; 568$ & $<0.001$ & 55 & 0.82 & $11.4(2.2)$ & $7.0 ; 15.8$ & $<0.001$ & 130 & 0.48 \\
\hline
\end{tabular}

a Estimated mean difference in yield $\left(\mathrm{kg} \mathrm{ha}^{-1}\right)$ and test weight $\left(\mathrm{kg} \mathrm{m}^{-3}\right)$ relative to a nontreated check $\left(\bar{D}^{(C)}\right)$, standard errors (SE) of $\bar{D}^{(C)}$, levels of significance $(P)$, between-study variance $\left(\hat{\sigma}_{D}^{2}\right)$, and lower and upper limits of the $95 \%$ confidence intervals $(C I)$ around $\bar{D}^{(C)}, p_{250}=$ estimated probability of obtaining a mean yield increase of $250 \mathrm{~kg} \mathrm{ha}^{-1}$, and $p_{12}=$ estimated probability of obtaining a mean test weight increase of $12 \mathrm{~kg} / \mathrm{m}^{3}$ in a new random study.

b Treatments consisted of demethylation inhibitor fungicides tebuconazole (TEBU), prothioconazole (PROT), propiconazole (PROP), or metconazole (METC) or quinone outside inhibitor fungicides pyraclostrobin (PYRA), azoxystrobin (AZOX), fluoxastrobin (FLUO), or trifloxystrobin (TRIF) applied at labelrecommended rates as either solo active ingredients or premixes, or sequentially during flag leaf emergence (Feekes growth stage 8-9, abbreviated as F9), at boot (Feekes 10; F10), at full head emergence (Feekes 10.5; F10.5), or at anthesis (Feekes 10.5.1; F10.5.1).

${ }^{\mathrm{c}}$ Standard treatment represents the mean of PROT_F10.5.1, TEBU+PROT_F10.5.1, and METC_F10.5.1.

Table 7. Estimated mean difference in grain yield and test weight relative to a standard set of treatments and corresponding statistics from network meta-analyses of the effects of fungicide treatments on yield and test weight of wheat grain harvested from Fusarium head blight affected plots ${ }^{\mathrm{a}}$

\begin{tabular}{|c|c|c|c|c|c|c|}
\hline \multirow[b]{2}{*}{ Treatment $^{\mathbf{b}}$} & \multicolumn{3}{|c|}{ Grain yield } & \multicolumn{3}{|c|}{ Test weight } \\
\hline & $\bar{D}^{(S)}(\mathrm{SE})$ & CI & $\boldsymbol{P}$ & $\bar{D}^{(S)}(\mathbf{S E})$ & CI & $P$ \\
\hline TEBU_F10.5.1 & $9.6(0.9)$ & $7.9 ; 11.4$ & $<0.001$ & $-6.2(1.0)$ & $-8.0 ;-4.3$ & $<0.001$ \\
\hline PYRA_F9 & $-186(43)$ & $-270 ;-103$ & $<0.001$ & $-12.1(1.7)$ & $-15.3 ;-8.8$ & $<0.001$ \\
\hline PYRA_F10 & $-227(45)$ & $-316 ;-138$ & $<0.001$ & $-13.5(2.2)$ & $-17.8 ;-9.2$ & $<0.001$ \\
\hline PYRA_F10.5 & $-132(42)$ & $-215 ;-51$ & 0.001 & $-11.7(1.7)$ & $-15.1 ;-8.4$ & $<0.001$ \\
\hline AZOX_F10.5 & $-220(67)$ & $-352 ;-88$ & 0.001 & $-14.9(2.4)$ & $-19.7 ;-10.1$ & $<0.001$ \\
\hline FLUO_F10.5 & $-172(75)$ & $-319 ;-24$ & 0.023 & $-13.6(2.9)$ & $-19.3 ;-7.9$ & $<0.001$ \\
\hline PYRA+METC_F10.5 & $-75(54)$ & $-181 ; 32$ & 0.170 & $-5.3(2.0)$ & $-9.2 ;-1.4$ & 0.008 \\
\hline AZOX+PROP_F10.5 & $-234(62)$ & $-356 ;-112$ & $<0.001$ & $-11.2(2.1)$ & $-15.3 ;-7.0$ & $<0.001$ \\
\hline TRIF+PROT_F10.5 & $-181(69)$ & $-316 ;-47$ & 0.008 & $-8.5(2.1)$ & $-12.5 ;-4.4$ & $<0.001$ \\
\hline PYRA_F9+METC_F10.5.1 & $28(37)$ & $-45 ; 100$ & 0.455 & $-4.6(1.7)$ & $-7.8 ;-1.3$ & 0.006 \\
\hline PYRA_F9 +TEBU+PROT_F10.5.1 & $96(46)$ & $5 ; 188$ & 0.039 & $-0.9(1.8)$ & $-4.5 ; 2.7$ & 0.626 \\
\hline PYRA_F9+TEBU_F10.5.1 & $60(5)$ & $-38 ; 158$ & 0.232 & $-4.4(2.2)$ & $-8.7 ;-0.1$ & 0.044 \\
\hline
\end{tabular}

${ }^{\text {a }}$ Estimated mean difference in yield $\left(\mathrm{kg} \mathrm{ha}^{-1}\right)$ and test weight $\left(\mathrm{kg} \mathrm{m}^{-3}\right)$ relative to a standard set of treatments $\left(\bar{D}^{(S)}\right)$, standard errors $\left(\right.$ SE) $\bar{D}^{(S)}$, levels of significance $(P)$, and lower and upper limits of the 95\% confidence intervals $(C I)$ around $\bar{D}^{(S)}$. The standard set of treatments represents the mean of PROT_F10.5.1, TEBU+PROT_F10.5.1, and METC_F10.5.1.

${ }^{\mathrm{b}}$ Treatments consisted of demethylation inhibitor fungicides tebuconazole (TEBU), prothioconazole (PROT), propiconazole (PROP), or metconazole (METC) or quinone outside inhibitor fungicides pyraclostrobin (PYRA), azoxystrobin (AZOX), fluoxastrobin (FLUO), or trifloxystrobin (TRIF) applied at label-recommended rates as either solo active ingredients or premixes, or sequentially during flag leaf emergence (Feekes growth stage 8-9, abbreviated as F9), at boot (Feekes 10; F10), at full head emergence (Feekes 10.5; F10.5), or at anthesis (Feekes 10.5.1; F10.5.1). 
likely to result in greater than a $25 \%$ control of IND in a new trial. Estimated $p_{25}^{(C)}$ values were approximately 0.40 for treatments applied at heading (PYRA_F10.5, TRIF+PROT_F10.5, and PYRA+METC_ F10.5) and less than 0.20 for the treatment applied at the boot stage (PYRA_F10), compared with $p_{25}^{(C)}$ values $>0.70$ for treatments that included an anthesis application of METC or TEBU+PROT following the early application of PYRA. The sequential QoI+DMI application treatments also had the highest $p_{50}^{(C)}$ values among treatments that included the two chemistries but none had a $p_{50}^{(C)}$ value as high as the standard (Fig. 2).

$D O N$. Estimated probability values for projected efficacy in terms of percent control relative to the nontreated check, for treatments that had a significant effect on DON (Table 2) are shown in Figure 3A, whereas probabilities for the risk of greater mean DON contamination following application of these same treatments relative to the mean in the check in a new randomly selected trial are shown in Figure 3B. As expected, treatments that consisted of an anthesis application of a DMI fungicide (either alone or following a QoI) had higher probability values than preanthesis treatments across all projected levels of control. The standard (used here as a measure of the mean efficacy of PROT_F10.5.1, TEBU+PROT_F10.5.1, and METC_F10.5.1) had the highest estimated $p_{25}^{(C)}$ and $p_{50}^{(C)}$ values ( 0.76 and 0.39 , respectively) followed by the sequential QoI+DMI application treatments PYRA_F9+METC_F10.5.1 $\left(p_{25}^{(C)}=0.60\right.$ and $\left.p_{50}^{(C)}=0.04\right)$ and PYRA_F9+TEBU+PROT_F10.5.1 $\left(p_{25}^{(C)}=0.59\right.$ and $\left.p_{50}^{(C)}=0.16\right)$ (Fig. 3A). Preanthesis treatments PYRA_F9, PYRA_F10, PYRA_F10.5, AZOX_F10.5, and AZOX+PROP_ F10.5 were the least likely to result in greater than $25 \%$ control of IND; they all had $p_{25}^{(C)}$ values below 0.008 and extremely low $p_{50}^{(C)}$ values (Fig. 3A).

The risk of DON increasing relative to the nontreated check by at least 50\% was extremely low for all treatments (Fig. 3B). Probability values for an increase remained low for the standard and for treatments that included an anthesis application of METC or TEBU+PROT following a Feekes 9 application of PYRA; they all had less than a 0.10 probability of increasing DON by 10 or even $25 \%$. However, the risk of DON increasing by at least $10 \%$ was relatively high (probability values between 0.65 and 0.75 ) for QoI-only treatments applied at boot or heading (PYRA_F10, PYRA_F10.5, and AZOX_F10.5) as well as the AZOX+PROP premix applied at heading (Fig. 3B). The Feekes 9 application of PYRA was the least likely of the preanthesis QoI-only treatments to increase DON by at least $10 \%$ but the probability of this eventuality was still 0.40 (which is interpreted as a $40 \%$ chance of increasing DON by $10 \%$ in a new trial). The probability of at least a $25 \%$ DON increase relative to the check was also fairly high (greater than 0.30) for PYRA_F10, PYRA_F10.5, AZOX_F10.5, and AZOX+PROP_F10.5, compared with less than 0.02 for the standard (Fig. 3B).

$Y L D$ and $T W$. For all tested treatments, the probability of a YLD increase relative to the nontreated check decreased as the projected YLD response increased (Fig. 4A). The standard and sequential application treatments had higher estimated probabilities than preanthesis QoI+DMI premixes and QoI-only treatments at all projected YLD increases. The highest probabilities were observed for treatments consisting of the application of the QoI PYRA at Feekes 9 followed by TEBU, METC, or TEBU+PROT at anthesis (Fig. 4A). These were all numerically higher than for the standard. For instance, the probability of a $250 \mathrm{~kg} \mathrm{ha}^{-1}$ increase in YLD $\left(p_{250}^{(C)}\right)$ was 0.85 for PYRA_F9+TEBU+PROT_F10.5.1, 0.82 for PYRA_F9+TEBU_ F10.5.1, and 0.80 for PYRA_F9+METC_F10.5.1, compared with 0.73 for the standard. Among the premixes, $p_{250}^{(C)}$ was highest for PYRA+METC_F10.5 (0.59) whereas PYRA_F10.5 had the highest $p_{250}^{(C)}$ among the QoI-only treatments.

Sequentially applied treatments (PYRA at Feekes 9 followed by a DMI at anthesis) also had the highest estimated probabilities for TW increases between 2 and $50 \mathrm{~kg} / \mathrm{m}^{3}$. Probabilities were lowest for QoIonly treatments. For instance, the probability of a $20 \mathrm{~kg} / \mathrm{m}^{3}$ increase in TW $\left(p_{20}^{(C)}\right)$ was less than 0.01 for QoI-only treatments (PYRA_F9, PYRA_F10, PYRA_F10.5, AZOX_F10.5, and FLUO_F10.5), between 0.03 (AZOX+PROT_F10.5) and 0.21 (PYRA+METC_ F10.5) for premixes, between 0.23 (PYRA_F9+TEBU_F10.5.1) and 0.38 (PYRA_F9+TEBU+PROT_F10.5.1) for treatments with a

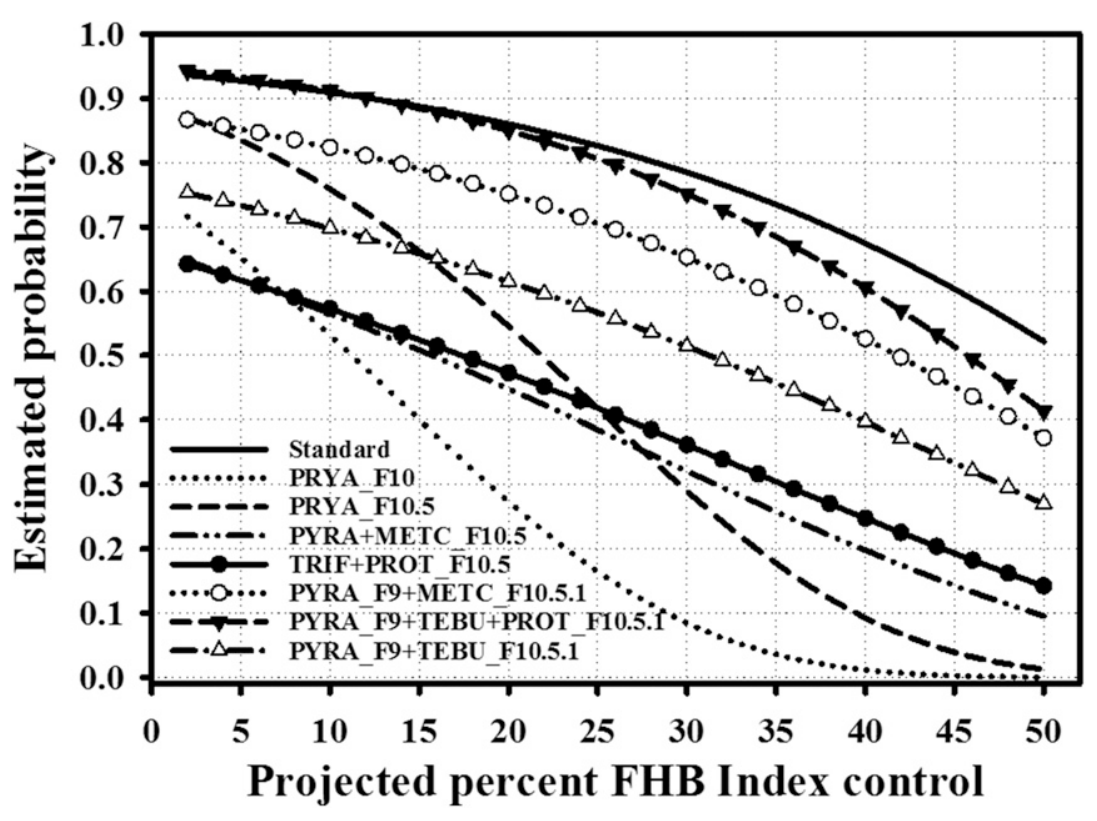

Fig. 2. Estimated probabilities of observing between a 2 and $50 \%$ decrease in Fusarium head blight (FHB) index relative to the nontreated check following the application of different fungicide treatments to FHB-affected plots in a new, randomly selected trial. Treatments consisted of demethylation inhibitor (DMI) fungicides tebuconazole (TEBU), prothioconazole (PROT), or metconazole (METC) or quinone outside inhibitor (Qol) fungicides pyraclostrobin (PYRA) or trifloxystrobin (TRIF) applied at label-recommended rates of active ingredients or premixes, or sequentially during flag leaf emergence (Feekes growth stage 8-9, abbreviated as F9), at boot (Feekes 10; F10), at full head emergence (Feekes 10.5; F10.5), or at anthesis (Feekes 10.5.1; F10.5.1). The standard, included here as a reference for comparison, represents the mean of the PROT_ F10.5.1, TEBU+PROT_F10.5.1, and METC_F10.5.1 treatments. In addition to the standard, probabilities were calculated only for those Qol-only and Qol+DMI combination treatments that had a statistically significant effect on FHB index. 
sequential application of a QoI and a DMI, and 0.40 for the standard (Fig. 4B). Unlike with YLD, none of the estimated probabilities of increase relative to the check for TW were numerically greater than the standard.

\section{Discussion}

A widely accepted recommendation for fungicide use in wheat is to not apply QoI-based products to manage FHB. In other words, if the risk of FHB is high, fungicides containing QoI such as azoxystrobin, pyraclostrobin, picoxystrobin, fluoxastrobin, or trifloxystrobin are generally not recommended for application at or close to anthesis, the growth stage at which fungicides are sprayed to suppress FHB and DON (McMullen et al. 2012). This is because some QoI were reported to be associated with increased levels of DON in grain harvested from FHB-affected plants (Ellner 2005; Zhang et al. 2009). This recommendation would also apply to premixes of QoI and DMI such as PYRA+METC, TRIF+PROT, and AZOX + propiconazole (PROP) but questions remain as to whether it should be expanded to preanthesis and even preheading applications of QoI-based fungicides. However, one cannot rely on results from individual studies to address these questions and draw conclusions about the effects of QoI, DMI, and QoI+DMI fungicides. This is because of the variability in the magnitude, significance, and, in some cases, direction of fungicide treatment effects on FHB, DON, YLD, and TW among active ingredients, treatment programs, and environments (in the generic sense), partly documented by the nonzero among-study treatmenteffect variances in this investigation $\left(\hat{\sigma}_{L}^{2}, \hat{\sigma}_{D}^{2}\right)$. For all of the questions addressed in this study, there were contrasting reports in the literature, as outlined below. However, access to multiple trials from several states and years, coupled with a network meta-analysis, allows us to draw general conclusions about population-average effects and, just as importantly, make projections as to expected outcomes for
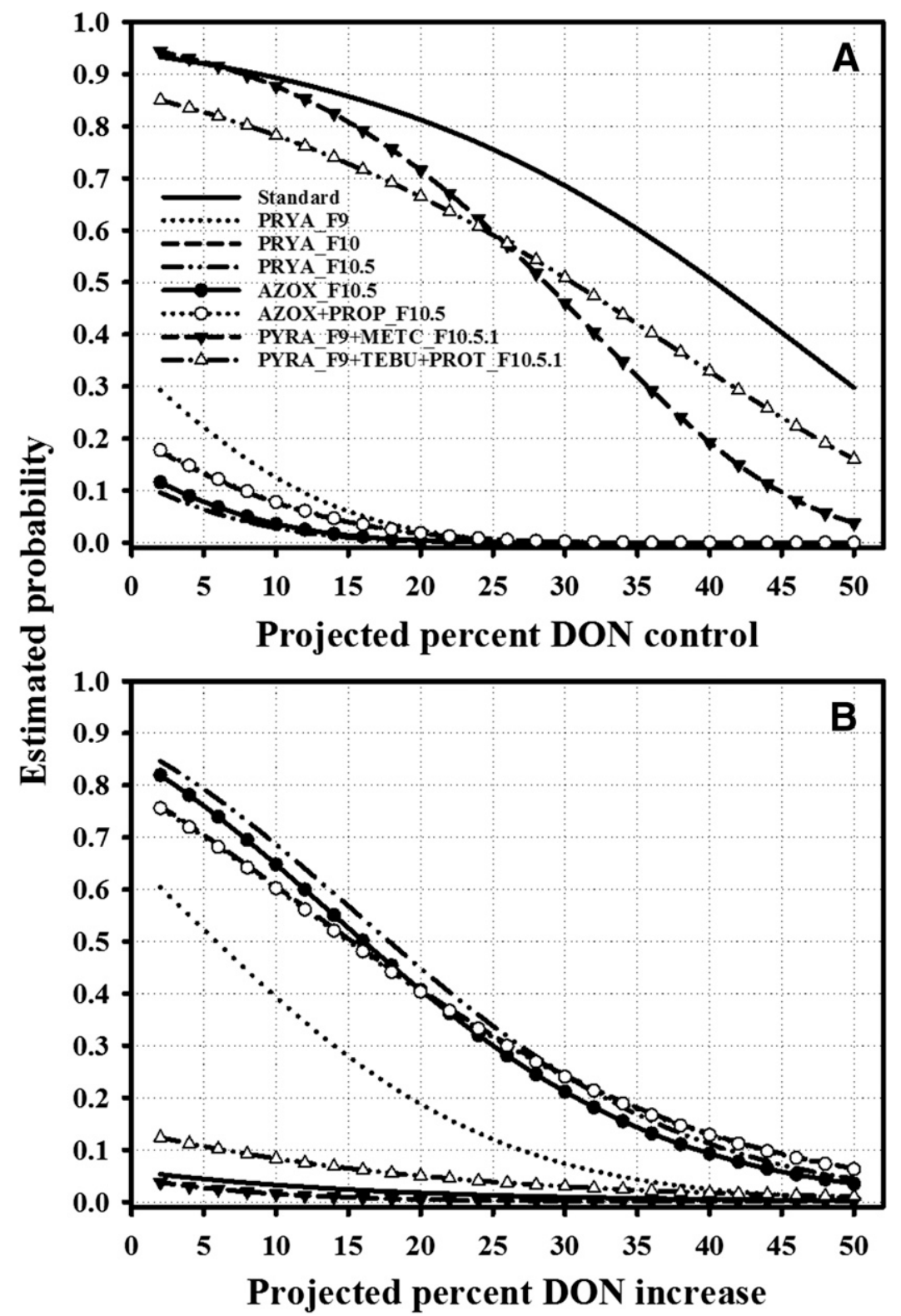

Fig. 3. Estimated probabilities of observing A, between 2 and $50 \%$ control and B, increase in deoxynivalenol (DON) contamination of harvested grain relative to the nontreated check following the application of different fungicide treatments to Fusarium head blight-affected plots in a new, randomly selected trial. Treatments consisted of demethylation inhibitor (DMI) fungicides tebuconazole (TEBU), prothioconazole (PROT), propiconazole (PROP), or metconazole (METC) or quinone outside inhibitor (Qol) fungicides pyraclostrobin (PYRA) or azoxystrobin (AZOX) applied at label-recommended rates as either solo active ingredients or premixes, or sequentially during flag leaf emergence (Feekes growth stage 8-9, abbreviated as F9), at boot (Feekes 10; F10), at full head emergence (Feekes 10.5; F10.5), or at anthesis (Feekes 10.5.1; F10.5.1). The standard, included here as a reference for comparison, represents the mean of the PROT_F10.5.1, TEBU+PROT_F10.5.1, and METC_F10.5.1 treatments. In addition to the standard, probabilities were calculated only for those Qol-only and Qol+DMI combination treatments that had a statistically significant effect on DON. 
future utilizations of the treatments evaluated here. The latter is done by explicitly utilizing information on the distribution of treatment effects (based on $\hat{\sigma}_{L}^{2}, \hat{\sigma}_{D}^{2}$ ), as either log response ratios or mean differences, across trials (Madden and Paul 2011; Paul et al. 2011). These meta-analytical results are invaluable for guiding the use of these fungicides for FHB and DON management.

Of the treatment programs evaluated in this study, those that included an anthesis application of a DMI fungicide resulted in the greatest reduction of mean IND and DON. This is consistent with what was expected, because the efficacy of this type of application program against FHB has been well documented (Edwards and Godley 2010; Paul et al. 2007, 2008; Yoshida et al. 2012). The wheat spike is considered most susceptible to infection from anthesis through the first several days of kernel development (Andersen 1948; Del Ponte et al. 2007; Siou et al. 2014). The efficacy of METC, TEBU+PROT, PROT, and TEBU in terms of mean percent control of IND relative to the nontreated check was comparable with that reported by Paul et al. $(2007,2008)$ from a previous quantitative synthesis of a subset of the data used here. For instance, based on a meta-analysis of data from 73 trials conducted prior to 2006, Paul et al. (2008) reported an overall mean IND control of $51.8 \%$ for TEBU+PROT. This is almost identical to the $51.5 \%$ estimated here from a meta-analysis of 292 trials, 213 of which included TEBU+PROT (140 of these trials were conducted between 2008 and 2013). The corresponding differences between percent control estimated in Paul et al. (2008) and in the current analysis for METC, PROT, and TEBU were 2.4, 1.6, and $-0.4 \%$, respectively.

DMI+QoI premix treatments applied at full head emergence (Feekes 10.5) were considerably less effective for IND control than the DMI-only treatments applied at anthesis. For instance, the efficacy of applying PYRA+METC at heading to control IND was $15.7 \%$, compared with $52.2 \%$ for METC alone applied at anthesis.

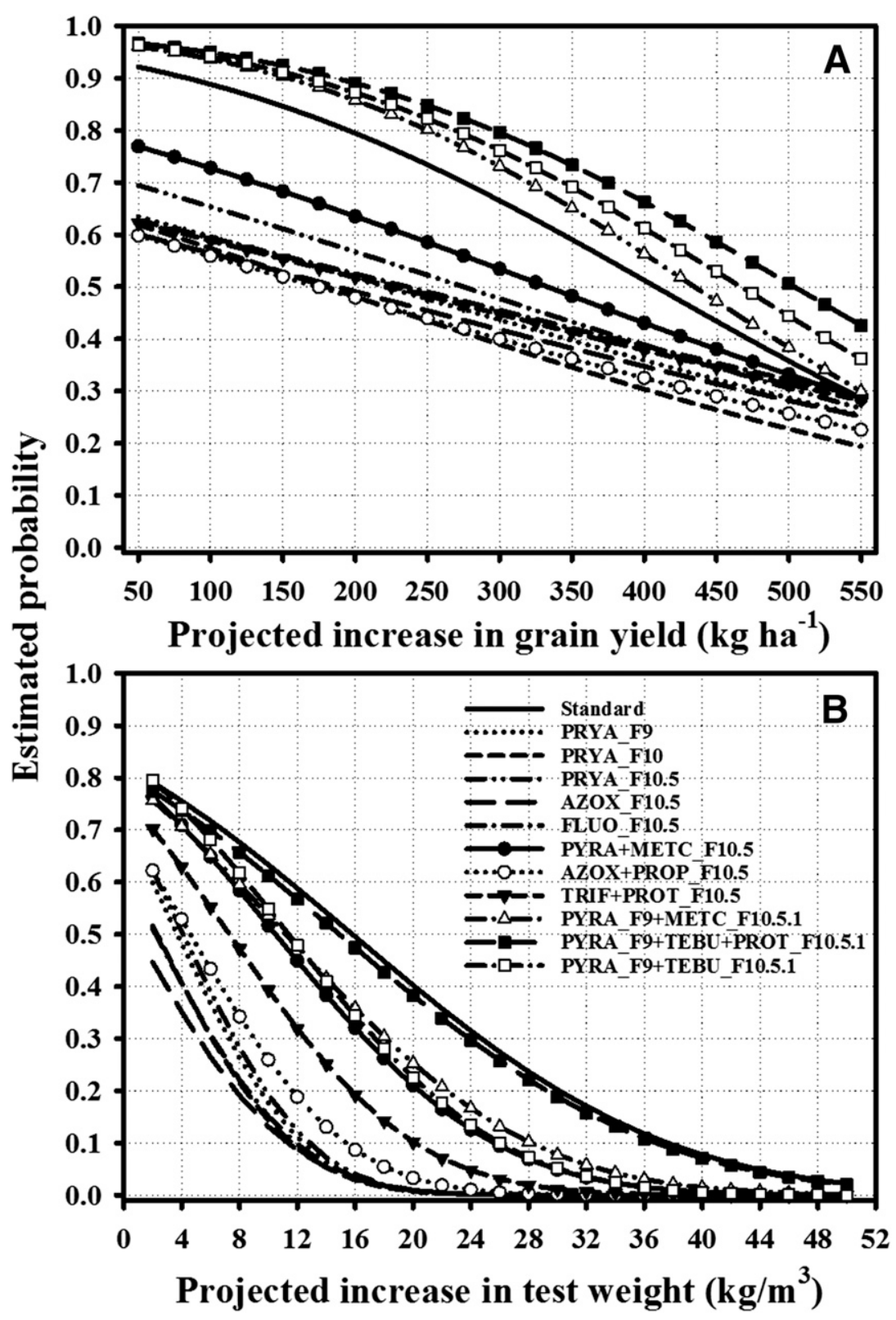

Fig. 4. Estimated probabilities of observing A, between a 50 and $550 \mathrm{~kg} \mathrm{ha}^{-1}$ increase in grain yield and $\mathbf{B}$, a 2 and $50 \mathrm{~kg} / \mathrm{m}^{3}$ increase in test weight relative to the nontreated check following the application of different fungicide treatments to Fusarium head blight-affected plots in a new, randomly selected trial. Treatments consisted of demethylation inhibitor fungicides tebuconazole (TEBU), prothioconazole (PROT), propiconazole (PROP), or metconazole (METC) or quinone outside inhibitor fungicides pyraclostrobin (PYRA), azoxystrobin (AZOX), fluoxastrobin (FLUO), or trifloxystrobin (TRIF) applied at label-recommended rates as either solo active ingredients or premixes, or sequentially during flag leaf emergence (Feekes growth stage 8-9, abbreviated as F9), at boot (Feekes 10; F10), at full head emergence (Feekes 10.5; F10.5), or at anthesis (Feekes 10.5.1; F10.5.1). The standard, included here as a reference for comparison, represents the mean of PROT_F10.5.1, TEBU+PROT_F10.5.1, and METC_F10.5.1. 
Several factors could have contributed to this inferior efficacy, including the fact that the rate of the DMI, the active ingredient with greater activity against $F$. graminearum (Cromey et al. 2002; Edwards et al. 2001; Pirgozliev et al. 2002), in the premix was lower than in the corresponding DMI-only treatment. Direct comparisons between heading and anthesis applications of the same rate of METC (in terms of active ingredient per hectare) provide support for this hypothesis. For instance, Paul et al. (2018) showed that, although a Feekes 10.5.1 application of METC $\left(90 \mathrm{~g}\right.$ a.i. ha $\left.{ }^{-1}\right)$ was more effective than Feekes 10.5 application of the same fungicide, the difference in efficacy was much smaller than observed in this study for the comparison between treatments consisting of the application of PYRA+METC at heading (7.4\% METC) and METC at anthesis (8.6\% METC). Application timing relative to when infection occurred could have also contributed to differences in efficacy between the premix of PYRA+METC applied at heading and METC alone applied at anthesis, and between TRIF+PROT applied at heading $(17 \%$ control of IND) and PROT alone applied at anthesis (50\% control of IND). This effect was likely further accentuated by the fact that trials in this study were artificially inoculated at or close to anthesis, which was hours or days before the anthesis treatments were applied and several days after heading treatments were applied. This likely put the preanthesis treatments at a disadvantage in terms of providing protection against infection, although DMI fungicides are reported to have activity for several days after application (Daniels and Latin 2013). Results from studies in which QoI+DMI mixtures were applied at anthesis reported efficacy comparable with and even greater than corresponding DMI-only treatments (Blandino et al. 2006; Dardis and Walsh 2000; Edwards et al. 2001).

As a group, the QoI-only treatments, all of which were applied prior to anthesis, resulted in highly variable responses in terms of mean percent IND reduction. For instance, among the treatments applied at heading, only PYRA resulted in a significant reduction in mean IND relative to the check. AZOX and FLUO had numerically contrasting but nonsignificant effects. These results are at odds with those reported by Pirgozliev et al. (2002) from a single greenhouse study which showed that the application of AZOX at heading reduced FHB severity (equivalent to IND as defined in our study) by 6 to $51 \%$ (depending on the experiment, species of Fusarium used for inoculation, and rate of active ingredient applied) relative to the check. As was the case in our study, Chen et al. (2012) observed that PYRA (25\% Cabrio applied at 150 and $225 \mathrm{~g}$ a.i./ha) in one study was effective against IND in both curative and preventative treatment programs. However, they reported efficacy ( $>70 \%$ control) that was considerably greater than the mean of $22 \%$ observed for PYRA applied at heading in our study. Caldwell et al. (2017) also reported relatively high levels of FHB control (40 to 50\%) with a single preanthesis (flag leaf) application of PYRA (Headline 250 EC applied at $100 \mathrm{~g}$ a.i. $\mathrm{ha}^{-1}$ ) in both winter and spring wheat.

Interestingly, treatments consisting of an application of PYRA at Feekes 9 followed by a DMI at anthesis were also consistently less effective in lowering IND than the DMI-only anthesis treatments. For instance, the application of METC at anthesis led to an estimated $52 \%$ control of IND compared with $42 \%$ for the treatment consisting of an application of METC at anthesis following the application of PYRA at full flag leaf emergence. Although the sequential application treatments included a full-rate anthesis application of an effective DMI (Paul et al. 2008), applying PYRA at full flag leaf emergence apparently resulted in these treatments having greater mean IND than TEBU at anthesis, METC at anthesis, and TEBU+PROT at anthesis. Contrasts between the sequentially applied treatments and the standard (mean of PROT at anthesis, METC at anthesis, and TEBU+PROT at anthesis) determined that, on average, the former group did indeed have 11 to $41 \%$ greater mean IND than the latter group. This likely contributed to them being less effective in terms of mean percent control relative to the check. When applied at anthesis, QoI are known to be generally less effective for FHB reduction than DMI (Edwards et al. 2001; Pirgozliev et al. 2002); however, it is unclear how a flag leaf application of PYRA would influence the overall efficacy of an anthesis application of METC, TEBU, or TEBU+PROT, as our results indicated. The trends observed here are not consistent with those reported in some other individual studies (Caldwell et al. 2017; Chala et al. 2003). For instance, Caldwell et al. (2017) reported that sequential QoI+DMI treatments (very similar to the three evaluated in our study) resulted in comparable and sometimes greater IND reduction relative to the check than DMI-only treatments applied at anthesis. However, our results are from many trials over a diversity of environments.

As was the case with IND, treatments consisting of a single application of a DMI at anthesis also provided the greatest efficacy against DON. However, the magnitude of the treatment effects in terms of estimated mean percent control was somewhat lower than reported by Paul et al. (2008) from a previous meta-analysis of a smaller subset of the data. For TEBU+PROT, efficacy was estimated at $41.7 \%$ using data from 56 trials conducted from 2002 to 2005 (Paul et al. 2008) compared with $38.2 \%$ in this investigation based on data from 153 trials conducted between 2002 and 2013 (including the 56), a difference of $-3.5 \%$. Differences in estimated percent control for similar comparisons for METC, TEBU, and PROT were $0.4,-2.8$ and -2.6 , respectively.

Treatments that included a Feekes 9 application of PYRA followed by an anthesis application of METC or TEBU+PROT also reduced DON concentration relative to the nontreated check but the efficacy (based on percent control) was 19 and $8 \%$ lower, respectively, than the corresponding DMI-only anthesis application of METC and TEBU+PROT. This could be due, in part, to the fact that sequentially applied treatments also had greater mean IND levels than the comparative DMI-only treatments, and greater FHB is often correlated with greater DON concentrations (Paul et al. 2005b, 2006). An increase in mean DON relative to the check, as indicated by a negative percent control $(-6 \%)$ for the Feekes 9 application of PYRA, also serves as an explanation for the relatively reduced efficacy of the QoI+DMI sequential treatments. An increase in DON with PYRA reduces the magnitude of the mean difference between this treatment and the nontreated check, thus resulting in greater $\log$ response ratios and lower estimated mean percent controls. Following the Feekes 9 application of PYRA with an anthesis application of METC, TEBU+PROT, or TEBU did reduce the mean concentration of DON by 14 to $33 \%$ but this was not always sufficient to reduce DON to concentrations comparable with those observed for the anthesis-only DMI treatments. Sequentially applied treatments had between 13 and $24 \%$ greater DON then corresponding DMI-only anthesis treatments. Ellner (2005) also reported that, although an anthesis application of TEBU helped to reduce the negative effect of a flag leaf application of AZOX on DON, the combination treatment was much less effective than the anthesis-only TEBU treatment.

Treatments that included a QoI without an anthesis application of METC or TEBU+PROT did not reduce DON relative to the nontreated check. In fact, several QoI-only treatments resulted in increases in mean DON to concentrations greater than those estimated for the check, as indicated by negative percent control values. A Feekes 10 application of PYRA and Feekes 10.5 applications of PYRA, AZOX, or FLUO all resulted in increases in mean DON of a similar magnitude (13 to $18 \%$ ). This suggests that the DON response to a heading application of a QoI was not limited to a single active ingredient in this chemical group. The PYRA results showed that DON concentrations increased following applications at Feekes 9,10 , or 10.5 but the magnitude of the increase was greater at Feekes 10.5 (closest to anthesis) than at Feekes 9 or 10. Interestingly, the Feekes 10.5 and Feekes 10 PYRA application treatments increased mean DON by 18 and $15 \%$, respectively, while reducing mean IND by 22 and $11 \%$, respectively, over the nontreated check. The Feekes 9 PYRA and Feekes 10.5 AZOX treatments increased DON without having a significant effect on IND. These results are similar to those from studies investigating the influence of AZOX on associations between DON and fungal biomass (Simpson et al. 2001; Zhang et al. 2009), and suggest that the DON response, at least to some QoI treatments, was independent of visual symptom development or grain colonization. Increases in DON without corresponding increases in FHB (or fungal biomass) could be interpreted to mean that the fungicide stimulated late-season (post disease symptom development) DON production (Simpson et al. 2001; Zhang et al. 2009). 
Ellner (2005) and Oldenburg et al. (2001) also reported DON increases with both QoI-only (AZOX [Amistar]) and QoI+DMI combinations (kresoxim-methyl+epoxyconazole [Juwel] and kresoximmethyl+epoxyconazole+fenpropimorph [Juwel Top]) treatments applied at different growth stages between stem elongation (Feekes 6) and anthesis (Feekes 10.5.1) in individual studies. However, contrary to what was observed for PYRA in our study, Ellner (2005) reported that DON increased to much greater concentrations when Amster or Juwel Top were applied at the boot stage (Feekes 10) than at stem elongation or heading (Feekes 10.5). In addition, only one of the three QoI+DMI premix treatments evaluated in our study was associated with an increase in mean DON. Differences between our findings and those reported by others could be attributed to several factors, including fungicide chemistry, environmental conditions under which treatments were applied, rate of active ingredients, and cultivar resistance, some of which have been reported previously to be associated with DON responses to QoI and QoI+DMI combinations (Ellner 2005; Ramirez et al. 2004). For instance, in our study, the application of AZOX+PROP at Feekes 10.5, a combination treatment that included one of the least effective DMI against DON (Paul et al. 2008), was the only premix to increase DON relative to the check. Combinations that included METC or PROT, DMI with greater efficacy against FHB and DON (Paul et al. 2008), did not have a significant effect on DON. This was probably because the QoI and DMI counteracted each other. Reduced rates of the DMI and QoI in the premixes relative to the corresponding QoI- and DMI-only treatments could have also contributed to the observed response. For instance, the application of PYRA at Feekes 10.5 , a treatment with $23.6 \%$ of the QoI, increased DON by $18 \%$ relative to the check; METC_F10.5.1, with $8.6 \%$ of the DMI, reduced DON by $46 \%$; but a premix of the two, with only $12 \%$ of the QoI and $7.4 \%$ of the DMI, had no effect on DON.

All of the treatments examined in this study increased YLD and all but three increased TW relative to the nontreated check. In general, the greatest YLD and TW increases were observed for treatments with the highest percent control of IND and DON; those that included an anthesis application of a DMI. This was to be expected given that the health of the spike is important for YLD and quality (Lupton 1972). Fungicide treatments at anthesis may be effective against late-season foliar diseases such as Stagonospora leaf and glume blotch and the rusts (Salgado et al. 2017; Sylvester et al. 2018) and, as such, likely contributed further to YLD and TW by protecting upper leaves during grain development. The flag leaf is considered more important than glumes of the spike for grain fill (Lupton 1972). QoI-only and QoI+DMI premix treatments that were ineffective or had marginal efficacy against IND still resulted in increased YLD. These treatments, all applied prior to anthesis, likely contributed to the YLD and TW by reducing damage to the upper leaves by early-season diseases such as powdery mildew and Septoria leaf blotch (Bhathal et al. 2003; Marroni et al. 2006; Willyerd et al. 2015). In addition, several of the QoI have been reported to affect crop physiology and are believed to result in YLD increases even in the absence of disease (Grossman et al. 1999; Grossmann and Retzlaff 1997; Wu and von Tiedemann 2001). The effects of early QoI applications on early-season diseases and crop physiology, coupled with the effects of anthesis DMI treatments on reducing FHB and late-season diseases, are likely the reason that treatments consisting of an application of PYRA at Feekes 9 followed by a DMI at anthesis had the highest overall mean YLD increases relative to the check. However, this YLD increase was at the cost of two fungicide applications instead of one; a QoI+DMI sequential treatment program cost about twice as much as a DMI- or QoI-only program.

Under conditions of moderate to high FHB risk, as examined in this multilocation and multiyear investigation, we can draw the following conclusions.

1. Of the treatments evaluated here, DMI at anthesis are the most effective against FHB and DON and their use is most likely to result in effective FHB and DON control and least likely to increase DON in future trials.
2. Multiple QoI active ingredients increased DON over the nontreated checks and are the more likely of the two chemistries evaluated here to do so in future trials. This was the case even for those with no or marginal effects on IND. The risk of increased DON was greatest for applications made at heading but there was some evidence that applications of PYRA at boot or full flag leaf emergence growth stages may also be of concern in terms of increasing DON concentrations in the grain.

3. The effects of the QoI+DMI premixes on DON depended on the specific QoI and DMI active ingredient in the premix. An effective DMI, such as METC and PROT, reduced the negative effect of the QoI on DON as well as the probability of a DON increase in future QoI+DMI treatment applications.

4. Following a Feekes 9 application of PYRA with a subsequent anthesis application of an effective DMI helped reduce the negative effect of the QoI on DON but was not sufficient to completely offset this effect and achieve the efficacy of the anthesis-only DMI treatments. In fact, the Feekes 9 PYRA treatment appeared to reduce the efficacy of the DMI anthesis treatment in terms of DON control, although sequential treatments that include METC or TEBU+PROT are less likely to increase DON than QoI-only treatments in future trials.

5. Anthesis-only DMI and sequential QoI+DMI treatments resulted in the greatest mean YLD and TW increases. The sequential application of two fungicides increased YLD relative to the DMI-at-anthesis-only treatments, although this was done at the cost of two applications.

Our results suggest that one must be prudent when using QoIbased fungicide programs when the risk of FHB is moderate to high, particularly where a QoI is used without an effective DMI such as METC and PROT applied in combination or in sequence. The fact that DON contamination is a food safety concern that negatively affects the market value of wheat is well known (McMullen et al. 2012). Therefore, until such time that the mechanisms behind DON increase in response to QoI-based fungicide treatments are understood and strategies for preventing this from occurring are developed, we will continue to advise against the use of this class of fungicides under conditions favorable (wet and humid) for FHB. However, completely restricting the use of these products is not advisable because they have an important role in minimizing losses due to other economically important foliar diseases of wheat. Even if they are effective, DMI should not be the only fungicides applied at all growth stages for early- and late-season disease management; this is not a good fungicide resistance management strategy. Concerns regarding elevating DON concentrations and possible fungicide resistance underscore the importance of not relying on fungicides alone for disease management. For instance, planting a cultivar that is moderately resistant to FHB into a tilled field previously planted with a crop that is a nonhost to the species of Fusarium that incite FHB would reduce the risk of FHB, likely making early- and midseason QoI-based treatments less of a concern from a DON risk standpoint. Similarly, planting a cultivar with resistance to early and midseason foliar diseases would likely reduce the need for any preanthesis fungicide application, including QoI, and consequently reduce concerns regarding the effect of QoI on DON if conditions become favorable for FHB later in the season.

\section{Acknowledgments}

We thank W. Bardall, M. Wallhead, and the Snyder farm crew for assisting with the establishment and maintenance of plots in Wooster, $\mathrm{OH}$.

\section{Literature Cited}

Andersen, A. L. 1948. The development of Gibberella zeae head blight of wheat Phytopathology 38:595-611.

Anonymous. 2018. FRAC Code List 2018: Fungicides sorted by mode of action (including FRAC Code numbering). Online publication. Fungicide Resistance Action Committee. http://www.frac.info/

Bhathal, J. S., Loughman, R., and Speijers, J. 2003. Yield reduction in wheat in relation to leaf disease from Yellow (tan) spot and Septoria nodorum blotch. Eur. J. Plant Pathol. 109:435-443. 
Blandino, M., Haidukowski, M., Pascale, M., Plizzari, L., Scudellari, D., and Reyneri, A. 2012. Integrated strategies for the control of Fusarium head blight and deoxynivalenol contamination in winter wheat. Field Crops Res. 133: 139-149.

Blandino, M., Minelli, L., and Reyneri, A. 2006. Strategies for the chemical control of Fusarium head blight: Effect on yield, alveographic parameters and deoxynivalenol contamination in winter wheat grain. Eur. J. Agron. 25: 193-201.

Caldwell, C. D., MacDonald, D., Jiang, Y., Cheema, M. A., and Li, J. 2017. Effect of fungicide combinations for Fusarium head blight control on disease incidence, grain yield, and quality of winter wheat, spring wheat, and barley. Can. J. Plant Sci. 97:1036-1045.

Chala, A., Weinert, J., and Wolf, G. A. 2003. An integrated approach to the evaluation of the efficacy of fungicides against Fusarium culmorum, the cause of head blight of wheat. J. Phytopathol. 151:673-678.

Chen, Y., Zhang, A.-F., Gao, T.-C., Zhang, Y., Wang, W.-X., Ding, K.-J., Chen, L., Sun, Z., Fang, X.-Z., and Zhou, M.-G. 2012. Integrated use of pyraclostrobin and epoxiconazole for the control of Fusarium head blight of wheat in Anhui Province of China. Plant Dis. 96:1495-1500.

Cromey, M. G., Parkes, R. A., Sinclair, K. I., Lauren, D. R., and Butler, R. C. 2002. Effects of fungicides applied at anthesis on Fusarium head blight and mycotoxins in wheat. N. Z. Plant Prot. 55:341-346.

D’Angelo, D. L., Bradley, C. A., Ames, K. A., Willyerd, K. T., Madden, L. V., and Paul, P. A. 2014. Efficacy of fungicide applications during and after anthesis against Fusarium head blight and deoxynivalenol in soft red winter wheat. Plant Dis. 98:1387-1397.

Daniels, J. P., and Latin, R. 2013. Residual efficacy of fungicides for controlling brown patch on creeping bentgrass fairways. Plant Dis. 97:1620-1625.

Dardis, J., and Walsh, E. J. 2000. Studies on the effectiveness of metconazole in controlling Fusarium head blight caused by Fusarium culmorum in spring wheat (Triticum aestivum L.). Cereal Res. Commun. 28:443-448.

Del Ponte, E. M., Fernandes, J. M. C., and Bergstrom, G. C. 2007. Influence of growth stage on Fusarium head blight and deoxynivalenol production in wheat. J. Phytopathol. 155:577-581.

Dill-Macky, R. 2010. Fusarium head blight (scab). Pages 34-36 in: Compendium of Wheat Diseases and Pests, 3rd ed., W. W. Bockus, R. L. Bowden, R. M. Hunger, W. L. Morrill, T. D. Murray, and R. W. Smiley, eds. American Phytopathological Society, St. Paul, MN.

Dill-Macky, R., and Jones, R. K. 2000. The effect of previous crop residues and tillage on Fusarium head blight of wheat. Plant Dis. 84:71-76.

Edwards, S. G., and Godley, N. P. 2010. Reduction of Fusarium head blight and deoxynivalenol in wheat with early fungicide applications of prothioconazole. Food Addit. Contam. Part A 27:629-635.

Edwards, S. G., Pirgozliev, S. R., Hare, M. C., and Jenkinson, P. 2001. Quantification of trichothecene-producing Fusarium species in harvested grain by competitive PCR to determine efficacies of fungicides against Fusarium head blight of winter wheat. Appl. Environ. Microbiol. 67: 1575-1580.

Ellner, F. M. 2005. Results of long-term field studies into the effect of strobilurin containing fungicides on the production of mycotoxins in several winter wheat varieties. Mycotoxin Res. 21:112-115.

Grossman, K., Kwiatkowski, J., and Caspar, G. 1999. Regulation of phytohormone levels, leaf senescence and transpiration of the strobilurin kresoxim-methyl in wheat (Triticum aestivum). J. Plant Physiol. 154:805-808.

Grossmann, K., and Retzlaff, G. 1997. Bioregulatory effects of the fungicide strobilurin kresoxim-methyl in wheat (Triticum aestivum). Pestic. Sci. 50: 11-20.

Latin, R. 2006. Residual efficacy of fungicides for control of dollar spot on creeping bentgrass. Plant Dis. 90:571-575.

Lupton, F. G. H. 1972. Further experiments on photosynthesis and translocation in wheat. Ann. Appl. Biol. 71:69-79.

Madden, L. V., and Paul, P. A. 2011. Meta-analysis for evidence synthesis in plant pathology: An overview. Phytopathology 101:16-30.

Madden, L. V., Piepho, H.-P., and Paul, P. A. 2016. Statistical models and methods for network meta-analysis. Phytopathology 106:792-806.

Magan, N., Hope, R., Colleate, A., and Baxter, E. S. 2002. Relationship between growth and mycotoxin production by Fusarium species, biocides and environment. Eur. J. Plant Pathol. 108:685-690.

Marroni, M. V., Viljanen-Rollinson, S. L. H., Butler, R. C., and Deng, Y. 2006. Fungicide timing for the control of Septoria tritici blotch of wheat. N. Z. Plant Prot. 59:160-165.

McMullen, M., Bergstrom, G., De Wolf, E., Dill-Macky, R., Hershman, D., Shaner, G., and Van Sanford, D. 2012. A unified effort to fight an enemy of wheat and barley: Fusarium head blight. Plant Dis. 96:1712-1728

McMullen, M., Halley, S., Schatz, B., Meyer, S., Jordahl, J., and Ransom, J. 2008. Integrated strategies for Fusarium head blight management in the United States. Cereal Res. Commun. 36:563-568.

McMullen, M., Jones, R., and Gallenberg, D. 1997. Scab of wheat and barley: A reemerging disease of devastating impact. Plant Dis. 81:1340-1348.

Nason, M. A., Farrar, J., and Bartlett, D. 2007. Strobilurin fungicides induce changes to photosynthetic gas exchange that do not improve water use efficiency of plants grown under conditions of water stress. Pest Manage. Sci. 63:1191-1200.
Nganje, W. E., Bangsund, D. A., Leistritz, F. L., Wilson, W. W., and Tiapo, N. M 2004. Regional economic impacts of Fusarium head blight of wheat and barley. Rev. Agric. Econ. 26:332-347.

Oldenburg, E., Weinert, J., and Wolf, G. A. 2001. Effects of strobilurin containing fungicides on the deoxynivalenol content in winter wheat. Mycotoxin Res. 17:10-14

Paul, P. A., Bradley, C. A., Madden, L. V., Dalla Lana, F., Bergstrom, G. C., DillMacky, R., Wise, K. A., Esker, McMullen, M., Grybauskas, A., Kirk, W. W., Milus, E., and Ruden, K. 2018. Effects of pre- and post-anthesis applications of demethylation inhibitor fungicides on Fusarium head blight and deoxynivalenol in spring and winter wheat. Plant Dis. doi.org/10.1094/PDIS-03-18-0466-RE

Paul, P. A., El-Allaf, S. M., Lipps, P. E., and Madden, L. V. 2005a. Relationships between incidence and severity of Fusarium head blight on winter wheat in Ohio. Phytopathology 95:1049-1060.

Paul, P. A., Lipps, P. E., Hershman, D. E., McMullen, M. P., Draper, M. A., and Madden, L. V. 2007. A quantitative review of tebuconazole effect on Fusarium head blight and deoxynivalenol content in wheat. Phytopathology 97:211-220.

Paul, P. A., Lipps, P. E., Hershman, D. E., McMullen, M. P., Draper, M. A., and Madden, L. V. 2008. Efficacy of triazole-based fungicides for Fusarium head blight and deoxynivalenol control in wheat: A multivariate meta-analysis. Phytopathology 98:999-1011.

Paul, P. A., Lipps, P. E., and Madden, L. V. 2005b. Relationship between visual estimates of Fusarium head blight intensity and deoxynivalenol accumulation in harvested wheat grain: A meta-analysis. Phytopathology 95:1225-1236.

Paul, P. A., Lipps, P. E., and Madden, L. V. 2006. Meta-analysis of regression coefficients for the relationship between Fusarium head blight and deoxynivalenol content of wheat. Phytopathology 96:951-961.

Paul, P. A., Madden, L. V., Bradley, C. A., Robertson, A. E., Munkvold, G. P., Shaner, G., Wise, K. A., Malvick, D. K., Allen, T. W., Grybauskas, A., Vincelli, P., and Esker, P. 2011. Meta-analysis of yield response of hybrid field corn to foliar fungicides in the U.S. Corn Belt. Phytopathology 101:1122-1132.

Paul, P. A., McMullen, M. P., Hershman, D. E., and Madden, L. V. 2010. Metaanalysis of the effects of triazole-based fungicides on wheat yield and test weight as influenced by Fusarium head blight intensity. Phytopathology 100:160-171.

Pirgozliev, S. R., Edwards, S. G., Hare, M. C., and Jenkinson, P. 2002. Effect of dose rate of azoxystrobin and metaconazole on the development of Fusarium head blight and the accumulation of deoxynivalenol (DON) in wheat grain Eur. J. Plant Pathol. 108:469-478.

Ramirez, M. L., Chulze, S., and Magan, N. 2004. Impact of environmental factors and fungicides on growth and deoxynivalenol production by Fusarium graminearum isolates from Argentinean wheat. Crop Prot. 23:117-125.

Salgado, J. D., Lindsey, L., and Paul, P. A. 2017. Effects of row spacing and nitrogen rate on wheat grain yield and profitability as influenced by diseases. Plant Dis. 101:1998-2011.

Salgado, J. D., Madden, L. V., and Paul, P. A. 2014. Efficacy and economics of integrating in-field and harvesting strategies to manage Fusarium head blight of wheat. Plant Dis. 98:1407-1421.

Salgado, J. D., Madden, L. V., and Paul, P. A. 2015. Quantifying the effects of Fusarium head blight on grain yield and test weight in soft red winter wheat. Phytopathology 105:295-306.

Schabenberger, O., and Pierce, F. J. 2002. Contemporary Statistical Models for the Plant and Soil Sciences. CRC Press, New York.

Shaner, G. 2003. Epidemiology of Fusarium head blight of small grain cereals in North America. Pages 84-119 in: Fusarium Head Blight of Wheat and Barley. K. J. Leonard and W. R. Bushnell, eds. American Phytopathological Society, St. Paul, MN.

Simpson, D., Weston, G., Turner, J., Jennings, P., and Nicholson, P. 2001. Differential control of head blight pathogens of wheat by fungicides and consequences for mycotoxin contamination of grain. Eur. J. Plant Pathol. 107:421-431.

Siou, D., Gélisse, S., Laval, V., Repinçay, C., Canalès, R., Suffert, F., and Lannou, C. 2014. Effect of wheat spike infection timing on Fusarium head blight development and mycotoxin accumulation. Plant Pathol. 63:390-399.

Sylvester, P. N., Dalla Lana, F., Mehl, H. L., Collins, A. A., Paul, P. A., and Kleczewski, N. M. 2018. Evaluating the profitability of fungicide programs in mid-Atlantic soft-red winter wheat. Plant Dis. 102:1627-1637.

Willyerd, K. T., Bradley, C. A., Chapara, V., Conley, S. P., Esker, P., Madden, L. V., Wise, K. A., and Paul, P. A. 2015. Revisiting fungicide-based management guidelines for leaf blotch diseases in soft red winter wheat. Plant Dis. 99:1434-1444.

Willyerd, K. T., Li, C., Madden, L. V., Bradley, C. A., Bergstrom, G. C., Sweets, L. E., McMullen, M., Ransom, J. K., Grybauskas, A., Osborne, L., Wegulo, S. N., Hershman, D. E., Wise, K., Bockus, W. W., Groth, D., Dill-Macky, R., Milus, E., Esker, P. D., Waxman, K. D., Adee, E. A., Ebelhar, S. E., Young, B. G., and Paul, P. A. 2012. Efficacy and stability of integrating fungicide and cultivar resistance to manage Fusarium head blight and deoxynivalenol in wheat. Plant Dis. 96:957-967.

Wu, Y.-X., and von Tiedemann, A. 2001. Physiological effects of azoxystrobin and epoxiconazole on senescence and the oxidative status of wheat. Pest. Biotechnol. Phys. 71:1-10.

Yoshida, M., Nakajima, T., Tomimura, K., Suzuki, F., Arai, M., and Miyasaka, A. 2012. Effect of the timing of fungicide application on Fusarium head blight and mycotoxin accumulation in wheat. Plant Dis. 96:845-851.

Zhang, Y., Fan, P., Zhang, X., Chen, C., and Zhou, M. 2009. Quantification of Fusarium graminearum in harvested grain by real-time polymerase chain reaction to assess efficacies of fungicides on Fusarium head blight, deoxynivalenol contamination, and yield of winter wheat. Phytopathology 99:95-100. 